Article

\title{
Study on Two Component Gas Transport in Nanopores for Enhanced Shale Gas Recovery by Using Carbon Dioxide Injection
}

\author{
Chaohua Guo ${ }^{1, * \mathbb{D}}$, Rongji $\mathrm{Li}^{1}{ }^{1}$ Xin Wang $^{2}$ and Hongji Liu ${ }^{1}$ \\ 1 Key Laboratory of Tectonics and Petroleum Resources Ministry of Education, China University of \\ Geosciences, Wuhan 430074, China; rongji_li@126.com (R.L.); liuhjcug@126.com (H.L.) \\ 2 Institute of Oceanographic Instrumentation, Shandong Academy of Sciences, Qingdao 266001, China; \\ wangx_sai@163.com \\ * Correspondence: chaohua.guo@cug.edu.cn
}

Received: 12 January 2020; Accepted: 28 February 2020; Published: 2 March 2020

\begin{abstract}
Injecting carbon dioxide to enhance shale gas recovery $\left(\mathrm{CO}_{2}\right.$-EGR) is a useful technique that has raised great research interests. Clear understanding of the two-component gas transport mechanisms in shale nanopores is the foundation for the efficient development of shale gas reservoir (SGR) and also the long-term geological storage of $\mathrm{CO}_{2}$. Although extensive studies on single-component gas transport and corresponding models in shale nanopores have been carried out in recent years, limited studies have been conducted on two-component or even multi-component gas transport models in shale nanopores. In this work, the shale nanopores were classified into inorganic and organic nanopores. The corresponding models for two-component gas transport were constructed. Mechanisms including Knudsen diffusion, slip flow, viscous flow, and molecular diffusion are considered in the inorganic pores. In the organic pores, due to existence of adsorption gas, surface diffusion is further considered besides the aforementioned mechanisms. Effects of pressure, temperature, fraction of organic nanopores, and gas concentration were analyzed. Results show that gas apparent permeability is negatively correlated with pressure, and positively correlated with temperature and organic nanopore fraction. As the concentration of $\mathrm{CH}_{4}$ decreases, the apparent permeability of $\mathrm{CH}_{4}$ increases continuously, while the apparent permeability of $\mathrm{CO}_{2}$ decreases. The permeability ratio of $\mathrm{CH}_{4}$ in the total permeability is negatively correlated with pressure and gas concentration ratio. Additionally, the contribution of transport mechanisms to the total gas apparent permeability has been analyzed. It is found that the surface diffusion contributes up to $5.68 \%$ to gas apparent permeability under high pressure. The contribution of molecular diffusion can reach up to $88.83 \%$ in mesopores under low pressure. Under high pressure and macropores, it contributes less than $1.41 \%$. For all situations, the contribution of viscous flow is more than $46.36 \%$, and its contribution can reach up to $86.07 \%$. Results of this study not only can improve the understanding of two-component gas transport in nanochannels, but also can lay the foundation for more reliable reservoir simulation of $\mathrm{CO}_{2}$-EGR.
\end{abstract}

Keywords: apparent permeability model; two-component gas; organic/inorganic nanopore; gas transport mechanism; shale gas reservoir

\section{Introduction}

Unconventional resources are becoming increasingly important due to the energy demand. Different from conventional reservoirs, shale gas reservoirs (SGRs) have developed various types of nanopores and have the characteristics of low porosity and permeability. In SGRs, the gas is stored in the interconnected pores or adsorbed on the organic matter (Figure 1). Due to multi-scale reservoirs and 
the existence of multiple gas types, complex transport mechanisms exist in SGRs, such as desorption, diffusion, slippage, and seepage [1]. Additionally, according to the field practice, the production of shale gas wells decreases sharply after exploitation. This leads to relevant studies on gas injection for enhancing shale gas production. Besides, shale has a large specific surface area and abundant pores. It has the potential to store a large amount of $\mathrm{CO}_{2}$, which is the main greenhouse gas. This not only can improve the recovery rate of shale gas, but also can realize permanent storage of $\mathrm{CO}_{2}$.

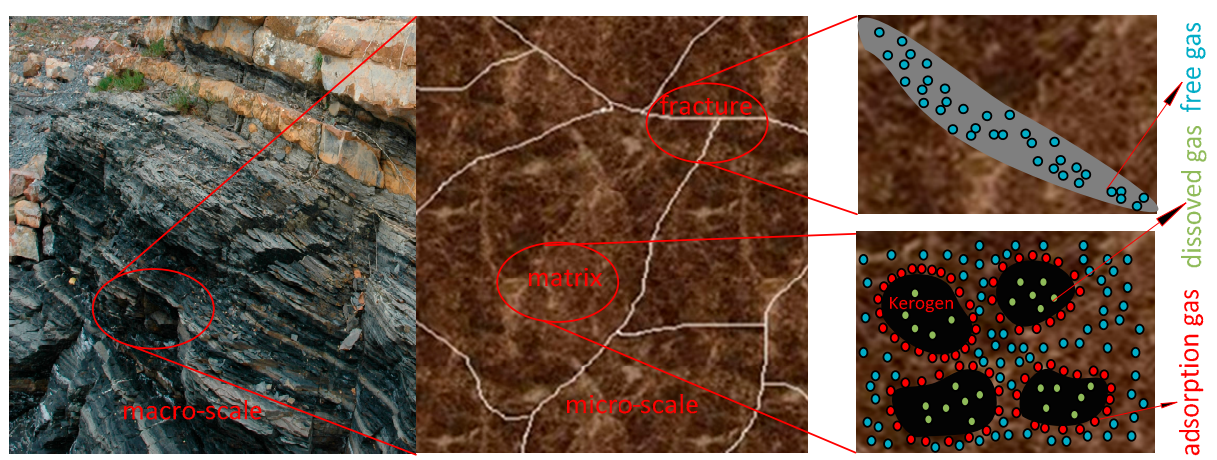

Figure 1. The diagram of gas distribution in shale gas reservoirs.

In the current studies regarding the gas apparent permeability models in nanopores, there are many studies for organic nanopores (ONPs). However, the studies for inorganic nanopores (IONPs) are relatively insufficient. In addition, the effect of water film is rarely considered in the current apparent permeability model for one-component gas. However, it can be learned from actual logging data that the water saturation is not negligible in SGRs, especially in the IONPs [2,3]. Although the water content in ONPs is controversial [4], the IONPs are extremely hydrophilic [5,6]. The water film is formed on the surface of IONPs in SGRs. Under this situation, $\mathrm{CH}_{4}$ and $\mathrm{CO}_{2}$ cannot be adsorbed on the pore surface. The gases can only concentrate in the center of the pore or adsorb on the water film $[7,8]$. Furthermore, current studies on gas apparent permeability mainly focus on single-component gas, i.e., pure methane. Limited studies have been carried out on the apparent permeability model for the two-component gas in SGRs.

Many scholars have already conducted studies on single-component gas transport in shale nanopores. Wang et al. [9] developed a fully coupled model by simulating shale gas reservoirs (SGRs), which considered gas adsorption, surface diffusion on the adsorption layer, stress sensitivity, and non-Darcy flow. The results by numerical simulation were consistent with the experimental data from the fields of Marcellus and Barrent. However, the effect of the water film was not considered in the established model. Additionally, the effect of inorganic nanopores was ignored. Feng et al. [10] established the apparent permeability model which considered the natural fractures, organic nanopores, and inorganic nanopores, etc. Song et al. [11] established a comprehensive model which considered gas adsorption-desorption and the diffusion of real gas. However, the effect of inorganic pores and water film were also not considered in their study. Cai et al. [12] also proposed the apparent permeability model by using a uniform diffusion coefficient to combine the effects of various gas transport mechanisms under different conditions. Singh et al. [13] established an apparent permeability model in which the Knudsen diffusion is regarded as the main gas transport mechanism. Therefore, this model is only suitable for the case with a Knudsen number less than unity. Additionally, the real gas effect was ignored in their model. Wu et al. [14] proposed a gas transport model for shale organic nanopores. In this model, multiple gas transport mechanisms and real gas effects were considered, but effects of water film and inorganic matter pores were neglected. Javadpour [15] developed a new gas transport model with considering slip flow and Knudsen diffusion. However, the impact of other gas transport mechanisms was ignored. Darabi et al. established the permeability model which considered effect of pressure and water film [16]. Similar to Javadpour's model [15], Knudsen diffusion and slip flow were the main gas flow mechanisms in their model. However, effect of real gas and inorganic nanopores were ignored. Zhang et al. [17] established 
the transport model for shale gas with considering multiple transport mechanisms, including Knudsen diffusion, viscous flow, and surface diffusion. Results show that surface diffusion cannot be neglected for small nanopores or under low pressure. However, the inorganic and organic nanopores in the shale were not separately processed in the model. Xu et al. [18] established the flow model for pure methane with considering Knudsen diffusion, surface diffusion, and gas adsorption, etc. In addition, the organic and inorganic nanopores were distinguished in their model. However, the effect of water film was not considered and the model was also only suitable for pure methane transport.

Some scholars have also initiated the study on two-component gas adsorption and transport in shale. Li et al. [19] established a dual-porosity double-permeability finite element model which considered the injection of $\mathrm{CO}_{2}$ and $\mathrm{N}_{2}$ into SGRs. Additionally, the effect of different gas injection schedules on shale gas development was evaluated. Akkutlu and Fathi [20] studied the injection of $\mathrm{CO}_{2}$ into SGRs by using numerical simulation method. Results showed that when $\mathrm{CO}_{2}$ entered the reservoir, the competitive adsorption of $\mathrm{CH}_{4}-\mathrm{CO}_{2}$ occurred in the reservoir. However, many gas transport mechanisms for two-component gas transport were not considered in their work. Kang et al. [21] concluded that the carbon dioxide was mainly adsorbed on the surface of organic nanopores, and the adsorption capacity of carbon dioxide was about four times of methane through laboratory experiments and numerical simulations. Sun et al. [22] proposed a new dual porosity model for $\mathrm{CO}_{2}$ injection into SGRs by considering viscous flow, Knudsen diffusion, and ordinary diffusion. However, effect of molecular diffusion and water film were not considered in their model. Based on literature review, it can be found that there are still limited studies on the two-component gas apparent permeability model. Additionally, there are many problems in the existing models: the transport mechanisms for two-component gas were not considered completely, and the organic and inorganic nanopores were not processed separately. However, the pore shape and gas transport mechanisms are not identical in these two kinds of nanopores. For example, the water film effect can be ignored in organic nanopores, whereas it should be considered in the inorganic nanopores.

Therefore, the two-component gas transport and apparent permeability model in shale matrix were constructed in this paper. The nanopores in the shale matrix are classified into two categories: inorganic and organic. Multiple gas transport mechanisms are considered, such as Knudsen diffusion, surface diffusion, molecular diffusion, and viscous flow, etc. Finally, the gas apparent permeability model for two-component $\mathrm{CH}_{4}-\mathrm{CO}_{2}$ in shale matrix was constructed and the effects of parameters on the apparent permeability of methane, carbon dioxide, and the mixture were analyzed. Results of this study can provide both theoretical and practical significance for the reservoir simulation of $\mathrm{CO}_{2}$-EGR, which can contribute to the efficient development of SGRs and the geological storage of $\mathrm{CO}_{2}$.

\section{Gas Transport Mechanisms in Shale Inorganic and Organic Nanopores}

Based on previous study $[5,23,24]$, the pores in the shale are generally divided into inorganic and organic nanopores according to the existence of organic matter or kerogen. Specially, for the organic nanopores which are formed in the kerogen, the pores can be characterized by cylindrical tubes [23-25]. For the inorganic pores which are formed in the clay minerals $[5,6]$, the pores can be characterized by silts [26,27]. Additionally, the gas transport mechanisms in inorganic and organic nanopores are different for the two-component gas $\left(\mathrm{CH}_{4}, \mathrm{CO}_{2}\right)$. In this work, the gas transport mechanisms in different pores are separately considered, and the two-component gas apparent permeability model is established. The diagram for the two-components gas transport mechanisms in shale organic nanopores is shown in Figure 2. For the inorganic nanopores, the surface diffusion can be ignored but the effect of water film should be considered. 


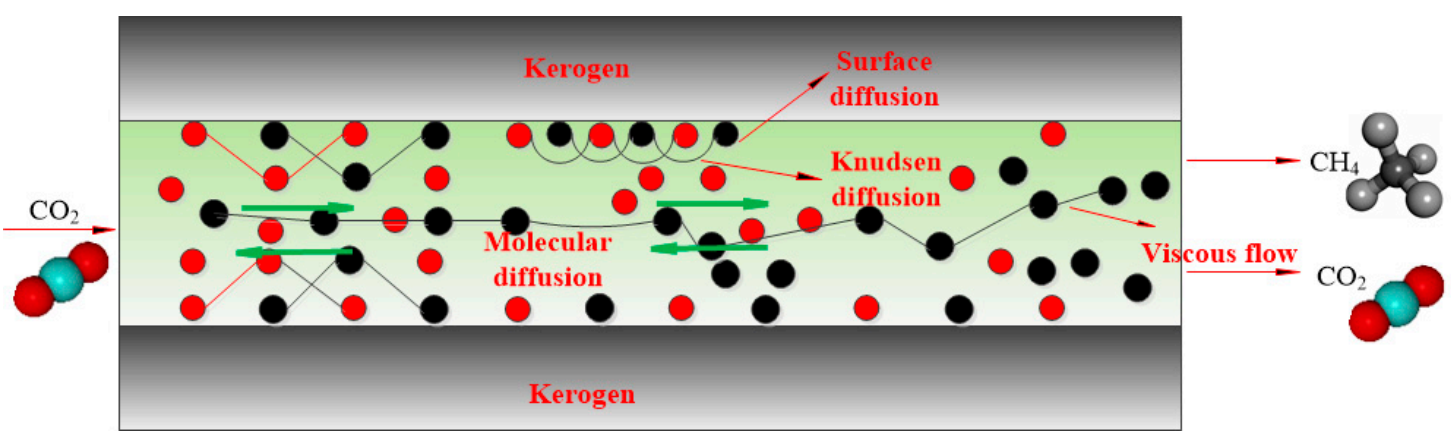

Figure 2. Two-component gas transport mechanisms in shale organic nanopores. The red balls stand for $\mathrm{CO}_{2}$ molecules and the black balls denote the $\mathrm{CH}_{4}$ molecules. In the inorganic nanopores, the surface diffusion can be ignored.

\subsection{Gas Transport Mechanisms in Organic Nanopores}

\subsubsection{Knudsen Diffusion}

As stated previously, the organic nanopore is commonly assumed as a cylindrical tube. If the forward direction is positive, the Knudsen diffusion equation considering the real gas effect can be expressed as follows [28]:

$$
J_{k}=-M D_{k} \nabla C
$$

where, $J_{k}$ represents mass flow due to Knudsen diffusion, $\mathrm{kg} /\left(\mathrm{m}^{2} \cdot \mathrm{s}\right) ; M$ represents the gas molecular weight, $\mathrm{kg} / \mathrm{mol} ; C$ represents the gas molar density, $\mathrm{mol} / \mathrm{m}^{3} ; D_{k}$ represents the Knudsen diffusion coefficient, $\mathrm{m}^{2} / \mathrm{s}$. The Knudsen diffusion coefficient $\left(D_{k}\right)$ can be expressed as follows:

$$
D_{k}=\frac{2 r}{3} \sqrt{\frac{8 R T}{\pi M}}
$$

Based on the gas state equation: $P V=n Z R T$ and the molar density: $c=\frac{n}{V}$, the following equation can be obtained:

$$
c=\frac{n}{V}=\frac{p}{Z R T}
$$

Combining Equations (1)-(3) and assuming the compressibility factor was not dependent to location and pressure, the mass flux due to Knudsen diffusion can be expressed as follows:

$$
J_{K}=-M D_{k} \nabla\left(\frac{p}{Z R T}\right)=\frac{-M D_{k}}{Z R T} \nabla p=-\frac{2 r M}{3 Z R T} \sqrt{\frac{8 R T}{\pi M}} \nabla p
$$

Additionally, the gas partial pressure for component $i$ in shale pores is

$$
p_{i}=p y_{i}
$$

where, $p$ represents the total pressure in shale, $\mathrm{Pa} ; y_{i}$ represents concentration ratio of gas component $i$. In this paper, it is assumed that the mass flow equation does not change as the gas component fraction changes, and the spatial gradient of the gas component fraction is ignored. Thus, the Knudsen diffusion equations for $\mathrm{CH}_{4} / \mathrm{CO}_{2}$ are obtained as follows:

$$
J_{K i}=-\frac{2 r M_{i} y_{i}}{3 Z_{i} R T} \sqrt{\frac{8 R T}{\pi M_{i}}} \nabla p
$$




\subsubsection{Viscous Flow}

According to the Hagen-Poiseuille equation, the mass flow equation of viscous flow can be calculated using following equation [29]:

$$
J_{v s}=-\rho \frac{r^{2}}{8 \mu} \nabla p
$$

where, $J_{v s}$ represents the mass flow of shale gas, $\mathrm{kg} /\left(\mathrm{m}^{2} \cdot \mathrm{s}\right) ; \rho$ is the gas density in shale, $\mathrm{kg} / \mathrm{m}^{3} ; \mu$ is the gas viscosity, Pa.s. According to the gas state equation, the densities of $\mathrm{CH}_{4}$ and $\mathrm{CO}_{2}$ can be expressed as follows:

$$
\rho_{i}=\frac{M_{i} p y_{i}}{Z_{i} R T}
$$

Therefore, the mass flow equations of viscous flow for two-component $\mathrm{CH}_{4}-\mathrm{CO}_{2}$ is

$$
J_{v s i}=-\frac{r^{2}}{8} \frac{M_{i} p y_{i}^{2}}{\mu_{i} Z_{i} R T} \nabla p
$$

\subsubsection{Surface Diffusion}

The volume of adsorbed gas usually accounts for $20 \%-85 \%$ of the total pore volume in SGRs. Therefore, the surface diffusion of adsorbed gas cannot be ignored in the micro-nanopores of SGRs. The mass flow equation of surface diffusion is [30]

$$
J_{s}=-D_{S} \frac{\phi C_{s}}{p \tau} \nabla p
$$

where, $J_{S}$ represents the mass flow of surface diffusion in shale, $\mathrm{kg} /\left(\mathrm{m}^{2} \cdot \mathrm{s}\right) ; D_{S}$ represents the gas surface diffusion coefficient, $\mathrm{m}^{2} / \mathrm{s} ; C_{s}$ represents the adsorption amount of real gas, $\mathrm{kg} / \mathrm{m}^{3} . C_{s}$ can be expressed as follows [30]:

$$
C_{s}=\frac{4 \theta M}{\pi d_{m}^{3} N_{A}}
$$

where, $\theta$ represents gas surface coverage, dimensionless; $M$ represents gas molecular weight, $\mathrm{kg} / \mathrm{mol} ; d_{m}$ represents the gas diameter molecule, $\mathrm{m}$; $N_{A}$ represents the Avogadro constant, $6.02214076 \times 10^{23} \mathrm{~mol}^{-1}$. The effect of gas surface coverage is considered, and $D_{S}$ can be calculated by using the following formula [31]:

$$
\begin{gathered}
D_{S}=D_{S 0} \frac{(1-\theta)+\frac{\kappa}{2} \theta(2-\theta)[H(1-\kappa)](1-\kappa) \frac{\kappa}{2} \theta^{2}}{\left(1-\theta+\frac{\kappa}{2} \theta\right)^{2}} \\
D_{S 0}=8.29 \times 10^{-7} T^{0.5} \exp \left(-\frac{\Delta H^{0.8}}{R T}\right) \\
H(1-\kappa)=\left\{\begin{array}{c}
0, \text { if } \kappa \geq 1 \\
1, \text { if } 0 \leq \kappa \leq 1
\end{array}\right. \\
\kappa=\frac{\kappa_{b}}{\kappa_{m}}
\end{gathered}
$$

where, $D_{S 0}$ is the surface diffusion coefficient when the surface coverage is $0, \mathrm{~m}^{2} / \mathrm{s} ; \kappa$ is the ratio of rate constant for blockage to rate constant for forward migration, dimensionless; $H(1-\kappa)$ is the Heaviside function, dimensionless; $\kappa_{m}$ is rate constant for forward migration, $\mathrm{m} / \mathrm{s} ; \kappa_{b}$ is the constant rate for blockage, $\mathrm{m} / \mathrm{s}$. When $\kappa_{m}>\kappa_{b}$, surface diffusion will occur; when $\kappa_{b}>\kappa_{m}$, the gas molecules are blocked and the surface diffusion will disappear. Therefore, the mass flow equations of $\mathrm{CH}_{4} / \mathrm{CO}_{2}$ due to surface diffusion in the organic matter pores can be expressed as follows:

$$
J_{s i}=-D_{S i} \frac{4 \phi \theta_{i} M_{i}}{p \tau \pi d_{m(i)}^{3} N_{A}} \nabla p
$$




\subsubsection{Molecular Diffusion}

In the process of $\mathrm{CO}_{2}$-EGR, there are two-component gases $\left(\mathrm{CH}_{4}, \mathrm{CO}_{2}\right)$ in the organic matter pores. As the gas molecular weight of $\mathrm{CH}_{4}$ and $\mathrm{CO}_{2}$ are different, molecular velocities are also different in the organic nanopores. The molecular diffusion also exists in the SGRs and it can be expressed as

$$
J_{M A}=-D_{c o m}^{*} \nabla C_{A}
$$

where, $J_{M A}$ is the molecular diffusion mass flow of component $i, \mathrm{~kg} /\left(\mathrm{m}^{2} / \mathrm{s}\right) ; D_{c o m}^{*}$ is the effective molecular diffusion coefficient of components $A$ and $B$ in a porous media, $\mathrm{m}^{2} / \mathrm{s}$. The effective molecular diffusion coefficient $\left(D_{c o m}^{*}\right)$ can be expressed as follows [22]:

$$
\begin{gathered}
D_{c o m}^{*}=1.882922475 \times 10^{-2} \delta T^{3 / 2} \frac{\phi}{\tau} \sqrt{0.001 \times\left(\frac{1}{M_{A}}+\frac{1}{M_{B}}\right)} \frac{1}{P \sigma_{A B}^{2} \Omega_{A B}} \\
\sigma_{A B}=\frac{\sigma_{A}+\sigma_{B}}{2}
\end{gathered}
$$

where, $M_{A}$ and $M_{B}$ represent the molecular weight of gas $\mathrm{A}$ and $\mathrm{B}$, respectively, $\mathrm{kg} / \mathrm{mol} ; \tau$ represents the tortuosity, dimensionless; $\sigma$ represents the Lennard-Jones potential collision diameter, $\stackrel{o}{A} ; \Omega_{A B}$ represents the molecules collision integral, dimensionless; $\delta$ represents compression degree, dimensionless. $\delta$ can be expressed as follows:

$$
\delta=1-\frac{d_{g a s}}{d_{\text {pore }}}
$$

where, $d_{g a s}$ represents the gas molecule diameter, $\mathrm{nm}$; $d_{\text {pore }}$ represents the pore diameter, $\mathrm{nm}$. Combined with Equation (3), the mass flow equations for molecular diffusion of $\mathrm{CH}_{4} / \mathrm{CO}_{2}$ in organic matter pores can be expressed as

$$
J_{O M(i)}=-D_{c o m}^{*} \frac{y_{i}}{Z_{i} R T} \nabla p
$$

Therefore, the total mass flow equations of the two-component gas $\left(\mathrm{CH}_{4}, \mathrm{CO}_{2}\right)$ in the organic nanopores can be expressed as follows:

$$
J_{\text {org- } i}=J_{K(i)}+J_{v s(i)}+J_{s(i)}+J_{O M(i)}=\left[\frac{2 r M_{i}}{3 Z_{i} R T} \sqrt{\frac{8 R T}{\pi M_{i}}}+\frac{r^{2}}{8} \frac{M_{i}}{\mu_{i}} \frac{p y_{i}^{2}}{Z_{i} R T}+D_{S(i)} \frac{4 \phi \theta_{i} M_{i}}{p \tau \pi d_{m(i)}^{2} N_{A}}+D_{c o m}^{*} \frac{y_{i}}{Z_{i} R T}\right] \nabla p
$$

\subsubsection{Pore Radius Correction}

The surface coverage of $\mathrm{CH}_{4}$ and $\mathrm{CO}_{2}$ gas molecules can be obtained separately by considering the surface coverage $(\theta)$ of the adsorbed gas. The surface coverage of each component $i$ in the organic nanopores can be expressed as follows:

$$
r=r_{\max }-d_{\mathrm{CH} 4} \theta_{\mathrm{CH} 4}-d_{\mathrm{CO} 2} \theta_{\mathrm{CO} 2}=r_{\max }-\frac{p d_{\mathrm{CH} 4}}{p+p_{L(\mathrm{CH} 4)}}-\frac{p d_{\mathrm{CO} 2}}{p+p_{L(\mathrm{CO} 2)}}
$$

where, $r$ is the modified organic pore radius, $\mathrm{nm} ; r_{\max }$ is the pore radius when the surface coverage of the organic matter pores is zero, $\mathrm{nm} ; P_{L(\mathrm{CH} 4)}$ is the Langmuir pressure of the methane, $\mathrm{MPa} ; P_{L(\mathrm{CO})}$ is the Langmuir pressure of the carbon dioxide, $\mathrm{MPa} ; d_{\mathrm{CH} 4}$ and $d_{\mathrm{CO} 2}$ are the molecular diameter of methane and carbon dioxide, $\mathrm{nm}$.

\subsection{Gas Transport Mechanism in the Inorganic Nanopores}

Different from the organic nanopores, the inorganic nanopores are mainly formed by clay minerals. The clay minerals have greater hydrogen bond and dispersion force to water molecules. Therefore, it will be easier for the water molecules to be adsorbed on the pore walls of shale, which significantly reduces the gas adsorption. When water is present in the inorganic pores, water film will be located on 
the surface of pore wall. Additionally, most of the gas molecules will be accumulated at the center of the pore, and part of the gas molecules is adsorbed on the water film. Therefore, the solid-gas adsorption becomes solid-liquid-gas adsorption. In the inorganic pores, gas transport mechanisms for two-component gases mainly include Knudsen diffusion, slip-viscous flow, and molecular diffusion.

\subsubsection{Knudsen Diffusion}

With considering the shape factor of shale inorganic nanopores, the mass flow due to Knudsen diffusion in the inorganic nanopores can be expressed as [32]

$$
J_{R-k r(i)}=-B(\zeta) \frac{\phi H^{\prime 2}}{\tau W} \delta^{D_{f}-2} y_{i}\left(\frac{M_{i}}{2 \pi R T}\right)^{0.5} \nabla p
$$

where, $B(\zeta)$ is the shape factor of inorganic nanopores, dimensionless; $\phi$ is porosity, $\% ; \tau$ is tortuosity, dimensionless; $H^{\prime}$ is the width of the channel with considering water film effect, $\mathrm{m} ; y_{i}$ is the mole fraction of component $i$; $D_{f}$ is the fractal dimension of the inorganic nanopore, dimensionless. $B(\zeta)$ can be expressed as follows:

$$
B(\zeta)=\left\{\zeta^{2} \ln \left[\frac{1}{\zeta}+\sqrt{1+\frac{1}{\zeta^{2}}}\right]+\zeta \ln \left[\zeta+\sqrt{1+\zeta^{2}}\right]-\frac{\left(\zeta^{2}+1\right)^{3 / 2}}{3}+\frac{\left(1+\zeta^{3}\right)}{3}\right\}
$$

\subsubsection{Slip Flow}

The mass flow due to slip flow [32] in the inorganic nanopores can be expressed as follows:

$$
J_{R-v s r}=-A(\zeta) \frac{\phi}{\tau} \frac{h^{2}}{12 \mu} \frac{p M}{R T}\left(1+\alpha K_{n}\right)\left(1+\frac{6 K_{n}}{1-b K_{n}}\right) \nabla p
$$

where, $A(\zeta)$ is the shape factor of nanopore in slip flow, dimensionless; $K_{n}$ is the Knudsen number of the gas, dimensionless; $\alpha$ is rarefaction coefficient, dimensionless. The Knudsen number can be expressed as follows [32,33]:

$$
K_{n}=\frac{\lambda}{D}
$$

where, $\lambda$ is the mean free path of the gas molecules, $\mathrm{m} ; D$ is the height of the rectangular cross-section, $\mathrm{m}$. The mean free path for each component is [34]

$$
\lambda_{r(i)}=\frac{\mu_{i}}{p} \sqrt{\frac{\pi Z_{i} R T}{2 M_{i}}}
$$

Therefore, the gas Knudsen number with considering the water film can be expressed as

$$
K_{n(i)}=\frac{\mu_{i}}{p y_{i} H \prime} \sqrt{\frac{\pi Z_{i} R T}{2 M_{i}}}
$$

The slip mass flow equations for $\mathrm{CH}_{4} / \mathrm{CO}_{2}$ are given by

$$
J_{R-v s r(i)}=-A(\zeta) \frac{\phi}{\tau} \frac{h^{2}}{12 \mu_{i}} \frac{p y_{i} M_{i}}{R T}\left(1+\alpha_{i} K_{n(i)}\right)\left(1+\frac{6 K_{n(i)}}{1-b K_{n(i)}}\right) \nabla p
$$

\subsubsection{Molecular Diffusion}

In the inorganic nanopores, the mass flow equation of molecular diffusion is consistent with the equation in the organic nanopores. Therefore, the mass flow equation for $\mathrm{CH}_{4} / \mathrm{CO}_{2}$ is as follows : 


$$
J_{I M(i)}=-D_{c o m}^{*} \frac{y_{i}}{Z_{i} R T} \nabla p
$$

Therefore, the total mass flow equations for two-component gas in the inorganic nanopore can be expressed as

$$
\begin{gathered}
J_{\text {inorg-i }}=J_{R-k r(i)}+J_{R-v s r(i)}+J_{I M(i)} \\
=\left[B(\zeta) \frac{\phi H^{\prime 2}}{\tau W} \delta^{D_{f}-2} y_{i}\left(\frac{Z_{i} M_{i}}{2 \pi R T}\right)^{0.5}+A(\zeta) \frac{\phi}{\tau} \frac{h^{2}}{12 \mu_{i}} \frac{p y_{i} M_{i}}{R T}\left(1+\alpha_{i} K_{n i}\right)\left(1+\frac{6 K_{n i}}{1-b K_{n i}}\right)+D_{c o m}^{*} \frac{y_{i}}{Z_{i} R T}\right] \nabla p
\end{gathered}
$$

\subsubsection{Real Gas Effect}

In this study, the real gas effect is considered in both organic and inorganic nanopores. The following equations were applied for the calculation of gas viscosity, density, and compressibility factor. For the calculation of gas viscosity, the following formulas were used [35]:

$$
\begin{gathered}
\mu=\left(1 \times 10^{-4}\right) K \exp \left(\rho^{Y}\right) \\
K=\frac{(22.65+0.0388 M) T^{1.5}}{209.2+19.26 M+T} \\
X=3.448+\frac{986.4}{T}+0.01009 M \\
Y=2.447-0.2224 \\
\rho=\frac{p M}{Z R T}
\end{gathered}
$$

Additionally, for the gas compressibility factor, the formula is as follows [30,36]:

$$
\begin{aligned}
& Z_{i}=0.702 p_{r(i)}^{2} e^{-2.5 T_{r(i)}}-5.524 p_{r(i)} e^{-2.5 T_{r(i)}}+0.044 T_{r(i)}^{2}-0.164 T_{r(i)}+1.15 \\
& p_{r}=p / p_{c} \\
& T_{r}=T / T_{c}
\end{aligned}
$$

where, $p_{c}$ is critical pressure, $\mathrm{MPa} ; T_{c}$ is critical temperature, $\mathrm{K} ; p_{r}$ and $T_{r}$ are the reduced pressure and temperature.

\subsubsection{Pore Width Correction for Inorganic Nanopores}

As stated previously, the cross-section of inorganic nanopores can be assumed as rectangle. The schematic diagram of gas flow in inorganic pores is shown in Figure 3. Therefore, the inorganic nanopores can be simplified as slit pores. The aspect ratio $\zeta(\zeta>1)$ can be used to characterize the shape of the silt pores:

$$
\zeta=\frac{W}{H}
$$

where, $W$ represents the height of the slit pores, $\mathrm{m} ; H$ is the width of the slit pores, $\mathrm{m}$. When the inorganic nanopore contains water, the surface of the pore wall is covered with a water film with thickness of $h$. Therefore, the width of the slit pores is as follows:

$$
H^{\prime}=H-2 h
$$

where, $H^{\prime}$ represents the pore width with considering the water film effect, nm; $h$ represents the thickness of the water film, nm. 


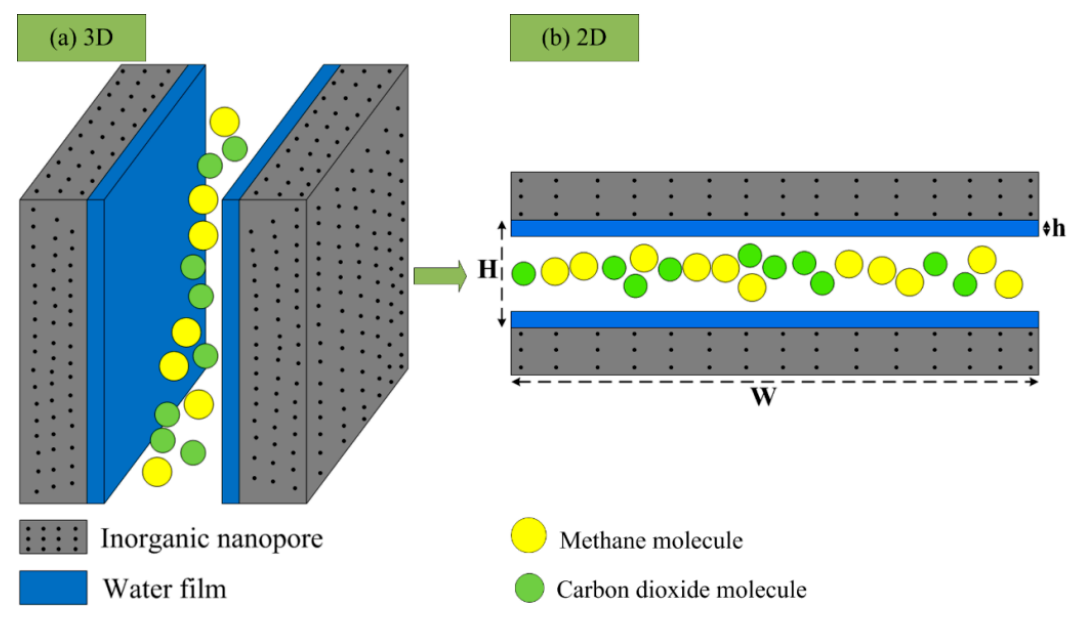

Figure 3. Schematic diagram of gas flow in inorganic pores.

\section{Construction of Apparent Permeability Model for Two-Component Gas}

\subsection{Mass Flow Equation}

The ratio of organic nanopores to inorganic nanopores varies in different shale gas reservoirs. If the fraction of organic nanopores in the total nanopores is expressed as $\eta$, the mass flow equations for $\mathrm{CH}_{4} / \mathrm{CO}_{2}$ in the total pores can be obtained as follows:

$$
\begin{gathered}
J_{i}=\eta J_{\text {org }-i}+(1-\eta) J_{\text {inorg }-i}=\eta\left[\frac{2 r M_{i}}{3 Z_{i} R T} \sqrt{\frac{8 R T}{\pi M_{i}}}+\frac{r^{2}}{8} \frac{M_{i}}{\mu_{i}} \frac{p y_{i}^{2}}{Z_{i} R T}+D_{S(i)} \frac{4 \phi \theta_{i} M_{i}}{p \tau \pi d_{m i}^{3} N_{A}}+D_{\text {com }}^{*} \frac{y_{i}}{Z_{i} R T}\right] \nabla p \\
+(1-\eta)\left[B(\zeta) \frac{\phi H^{\prime 2}}{\tau W} \delta^{D_{f}-2} y_{i}\left(\frac{Z_{i} M_{i}}{2 \pi R T}\right)^{0.5}+A(\zeta) \frac{\phi}{\tau} \frac{h^{2}}{12 \mu_{i}} \frac{p y_{i} M_{i}}{R T}\left(1+\alpha_{i} K_{n i}\right)\left(1+\frac{6 K_{n i}}{1-b K_{n i}}\right)+D_{\text {com }}^{*} \frac{y_{i}}{Z_{i} R T}\right] \nabla p
\end{gathered}
$$

\subsection{Apparent Permeability for Two-Component Gas}

The volume flux of component $i$ in inorganic and organic nanopores can be calculated as follows, respectively:

$$
\begin{aligned}
q_{\text {org }-i} & =\frac{J_{\text {org }-i} \pi r^{2}}{\rho_{i}} \\
q_{\text {inorg- } i} & =\frac{J_{\text {inorg }-i} W H^{\prime}}{\rho_{i}}
\end{aligned}
$$

According to the gas state equation, the density of $\mathrm{CH}_{4} / \mathrm{CO}_{2}$ is as follows:

$$
\rho_{i}=\frac{p y_{i} M_{i}}{Z_{i} R T}
$$

Therefore, the volume flux equations for two-component gas can be obtained:

$$
\begin{aligned}
& q_{i}=\eta q_{\text {org }-i}+(1-\eta) q_{\text {inorg }-i}=q_{\text {org-i }} \eta \pi r^{2}\left[\frac{2 r}{3 P y_{i}} \sqrt{\frac{8 R T}{\pi M_{i}}}+\frac{r^{2}}{8} \frac{y_{i}}{\mu_{i}}+D_{S(i)} \frac{4 \phi \theta_{i} Z_{i} R T}{p^{2} y_{i} \tau \pi d_{m i}^{3} N_{A}}+\frac{D_{c o m}^{*}}{p M_{i}}\right] \nabla p \\
& +(1-\eta) W H^{\prime}\left[B(\zeta) \frac{\phi H^{\prime 2}}{\tau W} \delta^{D_{f}-2} \frac{Z_{i}}{p}\left(\frac{R T}{2 \pi M_{i}}\right)^{0.5}+A(\zeta) \frac{\phi}{\tau} \frac{h^{2} Z_{i}}{12 \mu_{i}}\left(1+\alpha_{i} K_{n i}\right)\left(1+\frac{6 K_{n i}}{1-b K_{n i}}\right)+\frac{D_{c o m}^{*}}{p M_{i}}\right] \nabla p
\end{aligned}
$$

According to Darcy's law, the apparent permeability model of two-component gas can be expressed as

$$
\begin{gathered}
k_{a p p-i}=\eta\left[\frac{2 r \mu_{i}}{3 P y_{i}} \sqrt{\frac{8 R T}{\pi M_{i}}}+\frac{y_{i} r^{2}}{8}+D_{S(i)} \frac{4 \phi \theta_{i} Z_{i} R T \mu_{i}}{p^{2} \tau \pi y_{i} d_{m i}^{3} N_{A}}+\frac{D_{c o m}^{*} \mu_{i}}{p M_{i}}\right]+ \\
(1-\eta)\left[B(\zeta) \frac{\phi H^{\prime 2}}{\tau W} \delta^{D_{f}-2} \mu_{i} \frac{Z_{i}}{p}\left(\frac{R T}{2 \pi M_{i}}\right)^{0.5}+A(\zeta) \frac{\phi}{\tau} \frac{h^{2} Z_{i}}{12}\left(1+\alpha_{i} K_{n i}\right)\left(1+\frac{6 K_{n i}}{1-b K_{n i}}\right)+\frac{D_{c o m}^{*} \mu_{i}}{p M_{i}}\right]
\end{gathered}
$$


Additionally, the apparent permeability contributed by Knudsen diffusion $\left(k_{k n}\right)$, surface diffusion $\left(k_{s}\right)$, molecular diffusion $\left(k_{m}\right)$, viscous flow $\left(k_{v s}\right)$, and slip flow $\left(k_{s l}\right)$ can be expressed in Equation (38), respectively.

$$
\begin{gathered}
k_{k n(i)}=\frac{2 \eta r \mu_{i}}{3 p y_{i}} \sqrt{\frac{8 R T}{\pi M_{i}}}+(1-\eta) B(\zeta) \frac{\phi H^{\prime 2}}{\tau W} \delta^{D_{f}-2} \mu_{i} \frac{Z_{i}}{p}\left(\frac{R T}{2 \pi M_{i}}\right)^{0.5} \\
k_{s(i)}=\frac{4 \eta D_{S(i)} \phi \theta_{i} Z_{i} R T \mu_{C H 4}}{p^{2} \tau \pi y_{i} d_{m(i)}^{3} N_{A}} \\
k_{m(i)}=\frac{D_{c o m}^{*} \mu_{i}}{p M_{i}} \\
k_{v s(i)}=\frac{\eta y_{i} r^{2}}{8} \\
k_{s l(i)}=(1-\eta) A(\zeta) \frac{\phi}{\tau} \frac{h^{2} Z_{i}}{12}\left(1+\alpha_{i} K_{n(i)}\right)\left(1+\frac{6 K_{n(i)}}{1-b K_{n(i)}}\right)
\end{gathered}
$$

\section{Model Validation}

In order to validate the reliability of the proposed permeability model for two-component gas, the experiment results by Feng (2017) were utilized [37]. Shale samples from Longmaxi formation of Lower Silurian in Sichuan Basin were used in the experiment. The parameters used in the calculation can be found from the reference. The model built in this paper was also compared with existing model for two-component gas [38]. As shown in Figure 4, it can be found that the calculation results from the proposed model in this paper are highly correlated to the experimental results of Feng (2017). However, the permeability calculated by the existing Erfan's model is less than the experimental results, and there is a certain gap between the experimental results and Erfan's results. This is because the Erfan's models [38] did not completely consider the gas transport mechanisms in shale nanopores. For the proposed model in this paper, the gas transport mechanisms are comprehensively considered, which can well describe the two-component gas transport law in shale nanopores.

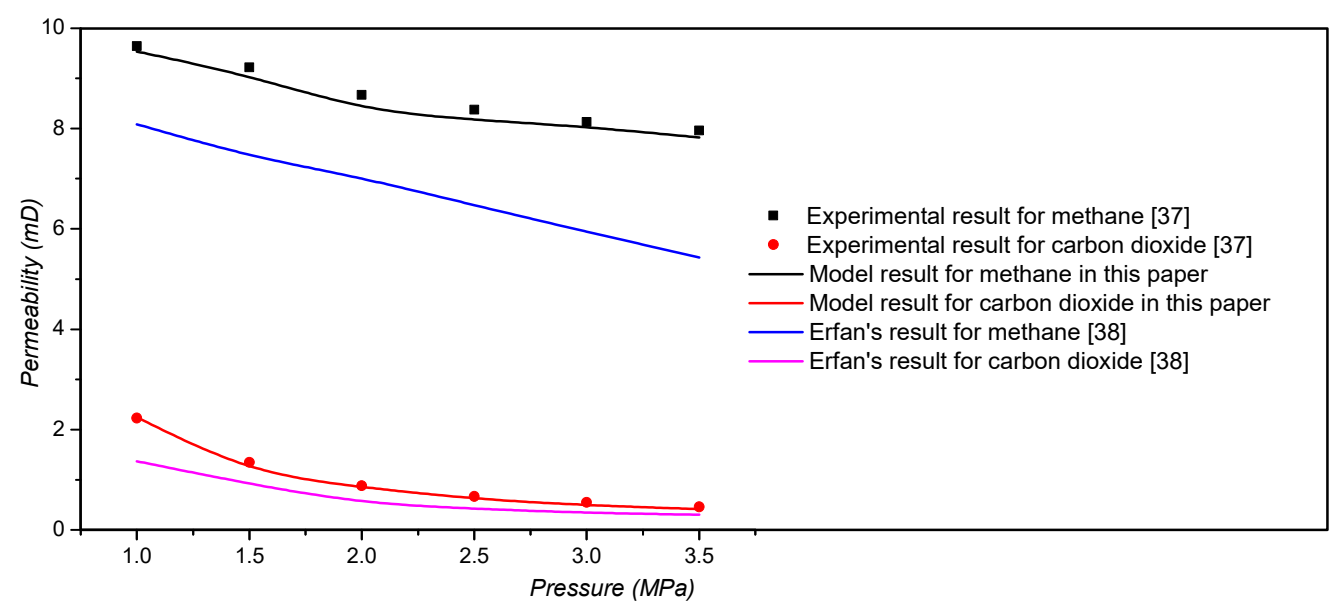

Figure 4. The comparison among the experimental data [37], existing model [38], and proposed model in this paper.

\section{Results and Analysis}

During the $\mathrm{CO}_{2}$-EGR process, many parameters will affect the gas transport for a two-component gas mixture. Here, the effect of parameters on gas transport capability were analyzed, including pressure, pore radius, fraction of organic nanopores, temperature, and gas concentration ratio. Additionally, contributions of different transport mechanisms were illustrated to show the sensitive ranges. The values of parameters used in the analysis are listed in Table 1. 
Table 1. Basic calculation parameters used in the analysis.

\begin{tabular}{|c|c|c|c|}
\hline Parameters & Symbol & Unit & Value \\
\hline Fraction of organic nanopores & $\eta$ & decimal & $0.2 / 0.4 / 0.5 / 0.6 / 0.8$ \\
\hline Pressure & $p$ & $\mathrm{~Pa}$ & $(0.1 / 1 / 5 / 10 / 20 / 100) \times 10^{6}$ \\
\hline Mole fraction of $\mathrm{CO}_{2}$ & $y_{\mathrm{CO} 2}$ & decimal & $0.9 / 0.7 / 0.5 / 0.3 / 0.2 / 0.1$ \\
\hline Universal gas constant & $R$ & $\mathrm{~J} / \mathrm{mol} \cdot \mathrm{K}$ & 8.314 \\
\hline Temperature & $T$ & $\mathrm{~K}$ & $293.15-465$ \\
\hline Molar mass of $\mathrm{CO}_{2}$ & $\mathrm{M}_{\mathrm{CO} 2}$ & $\mathrm{~kg} / \mathrm{mol}$ & 0.044 \\
\hline Equal adsorption heat & $\Delta H$ & $\mathrm{~J} / \mathrm{mol}$ & 16,000 \\
\hline Surface gas molecular blocking coefficient & $\kappa$ & dimensionless & 0.5 \\
\hline Avogadro constant & $N_{A}$ & $1 / \mathrm{mol}$ & $6.022 \times 10^{23}$ \\
\hline Langmuir pressure of $\mathrm{CO}_{2}$ & $P_{L(\mathrm{CO} 2)}$ & $\mathrm{Pa}$ & $1.38 \times 10^{6}$ \\
\hline Langmuir pressure of $\mathrm{CH}_{4}$ & $P_{L(C H 4)}$ & pa & $2.07 \times 10^{6}$ \\
\hline Compression & $\delta$ & dimensionless & 1 \\
\hline Shape factor of the flat shape model & $\zeta$ & dimensionless & 4 \\
\hline Nanopore shape fractor with rectangular cross-section in Knudsen diffusion & $B(\zeta)$ & dimensionless & 10.641 \\
\hline Nanopore shape factor with rectangular cross-section in slip flow & $A(\zeta)$ & dimensionless & 1.372 \\
\hline Porosity & $\Phi$ & decimal & 0.05 \\
\hline Curvature & $\tau$ & dimensionless & 4.3 \\
\hline Fractal dimension of the nanopore & $D_{f}$ & dimensionless & 2.653 \\
\hline Thickness of water film & $h$ & $\mathrm{~m}$ & $0.2 \times 10^{-9}$ \\
\hline Gas sparse coefficient of $\mathrm{CH}_{4}$ & $\alpha_{\mathrm{CH} 4}$ & dimensionless & 1.13 \\
\hline Gas sparse coefficient of $\mathrm{CO}_{2}$ & $\alpha_{\mathrm{CO} 2}$ & dimensionless & 1.25 \\
\hline Width of inorganic nanopore & $H$ & $\mathrm{~m}$ & $(2-100) \times 10^{-9}$ \\
\hline
\end{tabular}

\subsection{Pressure ( $p)$ and Pore Radius $(r)$}

\subsubsection{Effect of $\mathrm{p}$ and $\mathrm{r}$ on Two-Component Gas Apparent Permeability}

The change of apparent permeability vs. pore radius under different pressures is shown in Figure 5. As it can be found from Figure 5, when the pore radius increases, the apparent permeability of $\mathrm{CH}_{4} / \mathrm{CO}_{2}$ increases. However, the permeability of $\mathrm{CH}_{4}$ and $\mathrm{CO}_{2}$ decreases when the pressure increases from 0.1 to $100 \mathrm{MPa}$. When the pressure is $0.1 \mathrm{MPa}$, the apparent permeability of $\mathrm{CH}_{4}$ is higher than the apparent permeability of $\mathrm{CO}_{2}$. It should be noted that the gas concentration ratio of $\mathrm{CH}_{4} / \mathrm{CO}_{2}$ is 3:7 in the analysis. This process indicates that a part of methane has been recovered. More carbon dioxide has been adsorbed on the surface of the pore wall which reduces the apparent permeability of carbon dioxide.

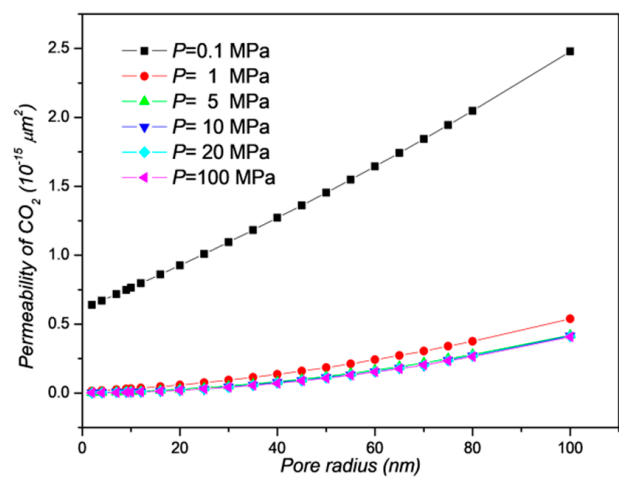

(a)

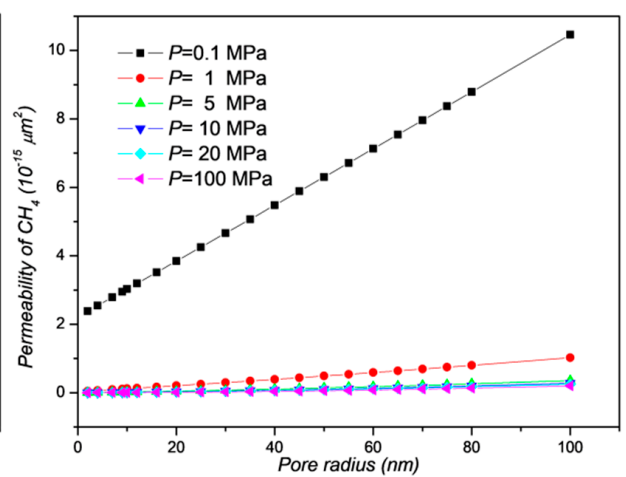

(b)

Figure 5. $(\mathbf{a}, \mathbf{b})$ Effect of pressure and pore radius on the gas permeability. The temperature is $345 \mathrm{~K}$. The mole ratio of $\mathrm{CH}_{4}$ vs. $\mathrm{CO}_{2}$ is 3:7. Additionally, the fraction of organic nanopores is $40 \%$. 


\subsubsection{Effect of $\mathrm{p}$ and $\mathrm{r}$ on Permeability Ratio}

In order to more clearly characterize the contribution of each component gas to the total gas flux, the term permeability ratio (PR) is defined in this paper. The PR is the percent of the apparent permeability for each component in the total apparent permeability, which can be calculated using the following equations.

$$
\begin{aligned}
& P R_{\mathrm{CH} 4}=\frac{K_{\mathrm{CH} 4}}{K_{\mathrm{CH}_{4}+K_{\mathrm{CO} 2}}} \times 100 \% \\
& P R_{\mathrm{CO} 2}=\frac{K_{\mathrm{CO}}}{K_{\mathrm{CH} 4}+K_{\mathrm{CO} 2}} \times 100 \%
\end{aligned}
$$

The change of PR vs. pore radius under different pressures is shown in Figure 6. As it can be found from Figure 6, with the increase of pressure and pore radius, the PR of methane is decreasing, while the PR of carbon dioxide is increasing (Figure 6). It indicates that the desorption capacity of methane decreases with pressure increasing and less free methane leads to the decrease of methane permeability. Additionally, it can be found that when the pressure is between 0.1 and $1 \mathrm{MPa}$, the permeability ratio of methane is more than $65 \%$ in the whole pore radius $(2-100 \mathrm{~nm})$. This denotes that more methane can be recovered. When the pressure is 5-20 MPa, the PR of methane is larger in a part of the pore radius. Within this pressure range, the recovery can be favorable for a specific pore radius range. Additionally, when the pressure is larger than $20 \mathrm{MPa}$, it can be found that PR of carbon dioxide is larger, which indicates that enhancing recovery in shale gas reservoirs is unfavorable in this situation.
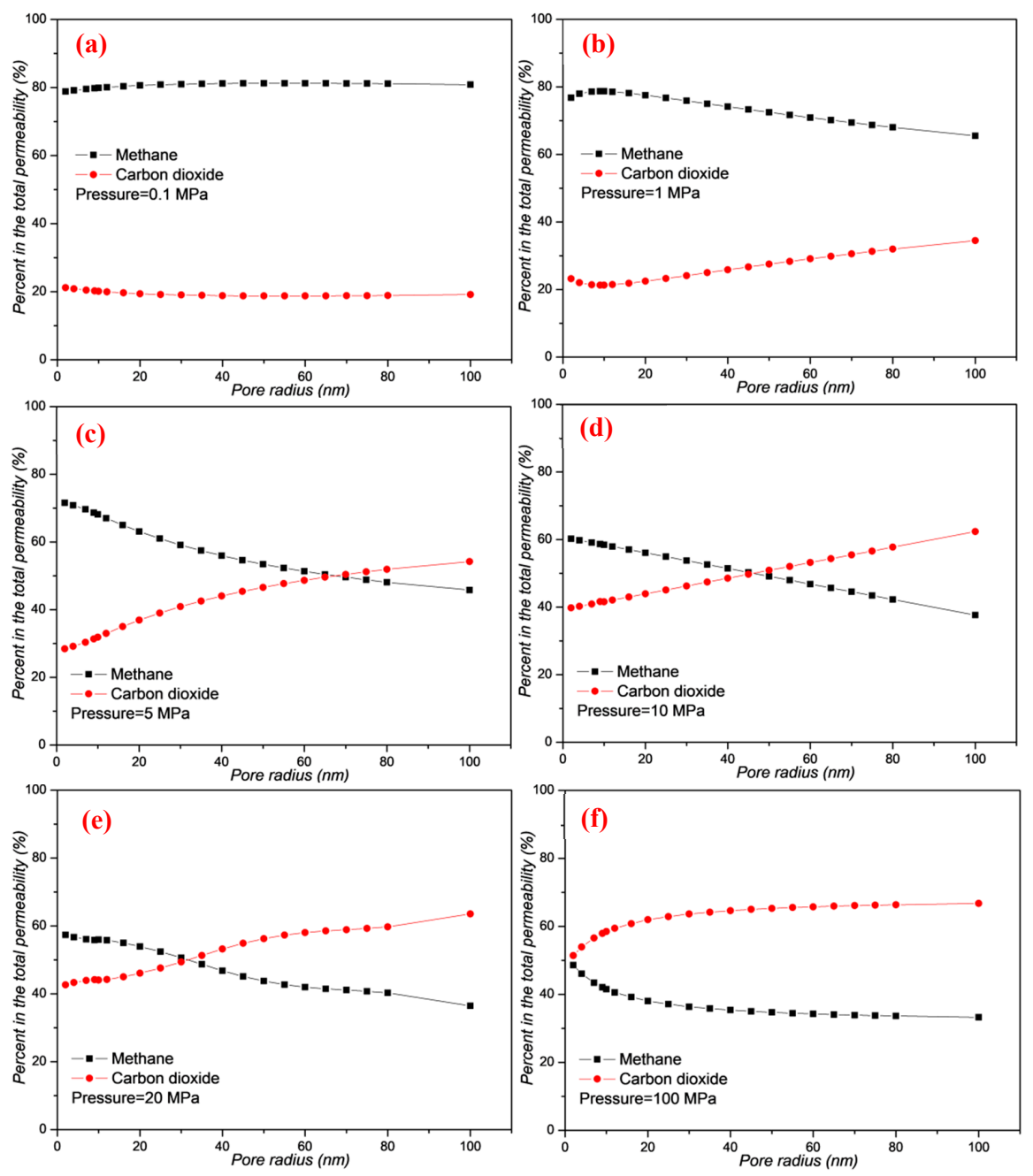

Figure 6. (a-f) Change of permeability ratio vs. pore radius and pressure. The temperature is $345 \mathrm{~K}$. The mole ratio of $\mathrm{CH}_{4}$ vs. $\mathrm{CO}_{2}$ is 3:7. Additionally, the fraction of organic nanopores is $40 \%$. 


\subsubsection{Contribution of Various Gas Mechanisms with $\mathrm{p}$ and $\mathrm{r}$ Changing}

It can be found from Figure 6 that PR of methane and carbon dioxide is changing with the pore radius. However, it is hard to analyze the reason why a different phenomenon exists: PR of methane is decreasing with pore radius and PR of carbon dioxide is increasing with pore radius. Therefore, a clear understanding regarding the contribution of each transport mechanism is required to illustrate such phenomenon. The contribution of each flow mechanism to the flow of methane and carbon dioxide is shown in Figures 7-11. The mechanisms include Knudsen diffusion, surface diffusion, molecular diffusion, slip flow, and viscous flow. $\gamma_{k n(i)}, \gamma_{s(i)}, \gamma_{m(i)}, \gamma_{v s(i)}$, and $\gamma_{s l(i)}$ are used to express the contribution of Knudsen diffusion, surface diffusion, molecular diffusion, viscous flow and slip flow to the total gas permeability, which are listed in Equation (40). The related parameters can be found from Equations (37) and (38):

$$
\gamma_{k n(i)}=\frac{k_{k n(i)}}{k_{a p p-i}} ; \gamma_{s(i)}=\frac{k_{s(i)}}{k_{a p p-i}} ; \gamma_{m(i)}=\frac{k_{m(i)}}{k_{a p p-i}} ; \gamma_{v s(i)}=\frac{k_{v s(i)}}{k_{a p p-i}} ; \gamma_{s l(i)}=\frac{k_{s l(i)}}{k_{a p p-i}}
$$

The contribution of Knudsen diffusion to the permeability $\left(\gamma_{k n(i)}\right)$ for methane and carbon dioxide is shown in Figure 7. As it can be found in Figure 7, the contribution of Knudsen diffusion increases initially, and then decreases with the pore radius. As the pressure increases, the peaks of the curves are closer to the $y$ axis (Figure 7). Additionally, it can be found in Figure $7 \mathrm{~b}$ that when the pressure is from 1 to $20 \mathrm{MPa}$, the apparent permeability of methane caused by Knudsen diffusion takes the dominant position in mesopores $(2-50 \mathrm{~nm})$. However, when the pressure is from 5 to $20 \mathrm{MPa}$, the apparent permeability of carbon dioxide caused by Knudsen diffusion is dominant in pores of radius $2-15 \mathrm{~nm}$ (Figure 7a). The main reason is that when the shale pores are close to the molecular mean free path, the collision probability of gas molecules with the pore wall is much higher than that of other collision types. Therefore, Knudsen diffusion is the main gas transport mechanism.
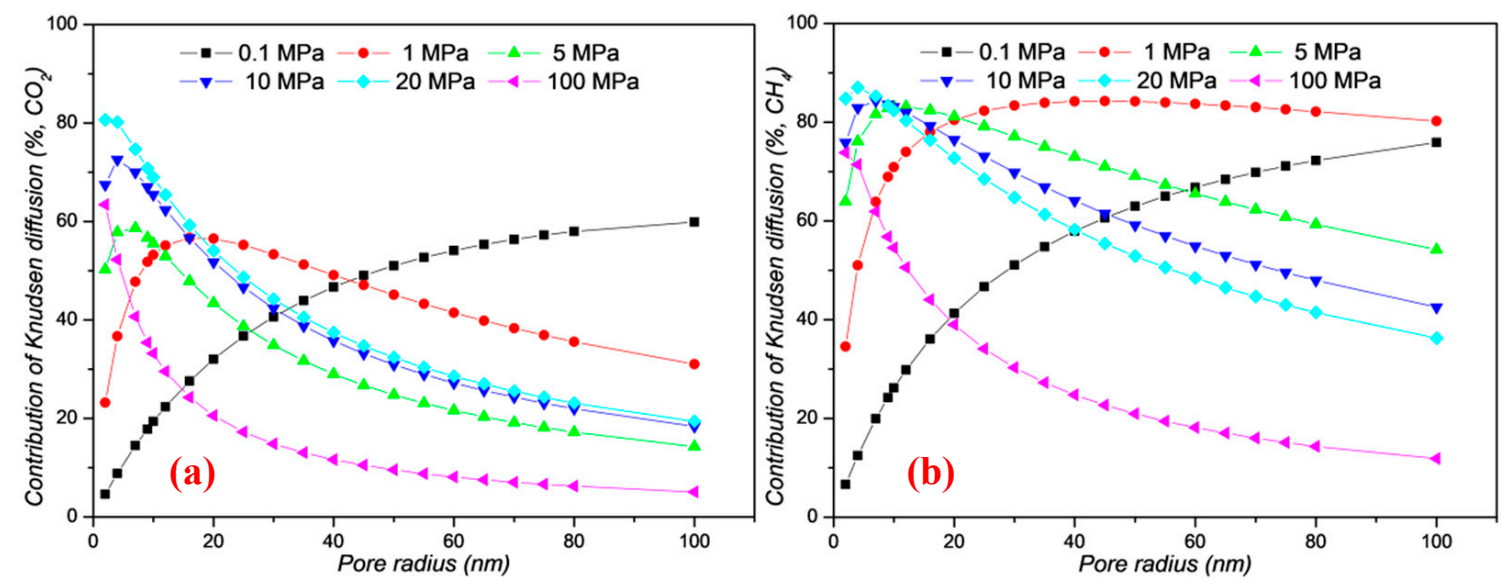

Figure 7. (a,b) Contribution of Knudsen diffusion to the gas permeability vs. pore radius.

The contribution of surface diffusion to the permeability $\left(\gamma_{s(i)}\right)$ for methane and carbon dioxide is shown in Figure 8. It can be found that the contribution of surface diffusion decreases with the increases of pore radius. $\gamma_{s}$ is a maximum of $5.68 \%$ under high pressure (Figure 8 ). Surface diffusion is caused by gas molecules adsorbed on the surface of pore wall, which moves along the pore wall. The apparent permeability caused by surface diffusion is lower in macropores $(>50 \mathrm{~nm})$. This is caused by the close distribution of gas molecules on the pore wall, which enables the gas molecules to move slowly on the pore wall. The contribution of slip flow to the permeability $\left(\gamma_{s l(i)}\right)$ has almost no change with the pore radius under pressure of $0.1-20 \mathrm{MPa}$ (Figure 9). Thus, the gas transport mechanism can be ignored in this pressure range. 

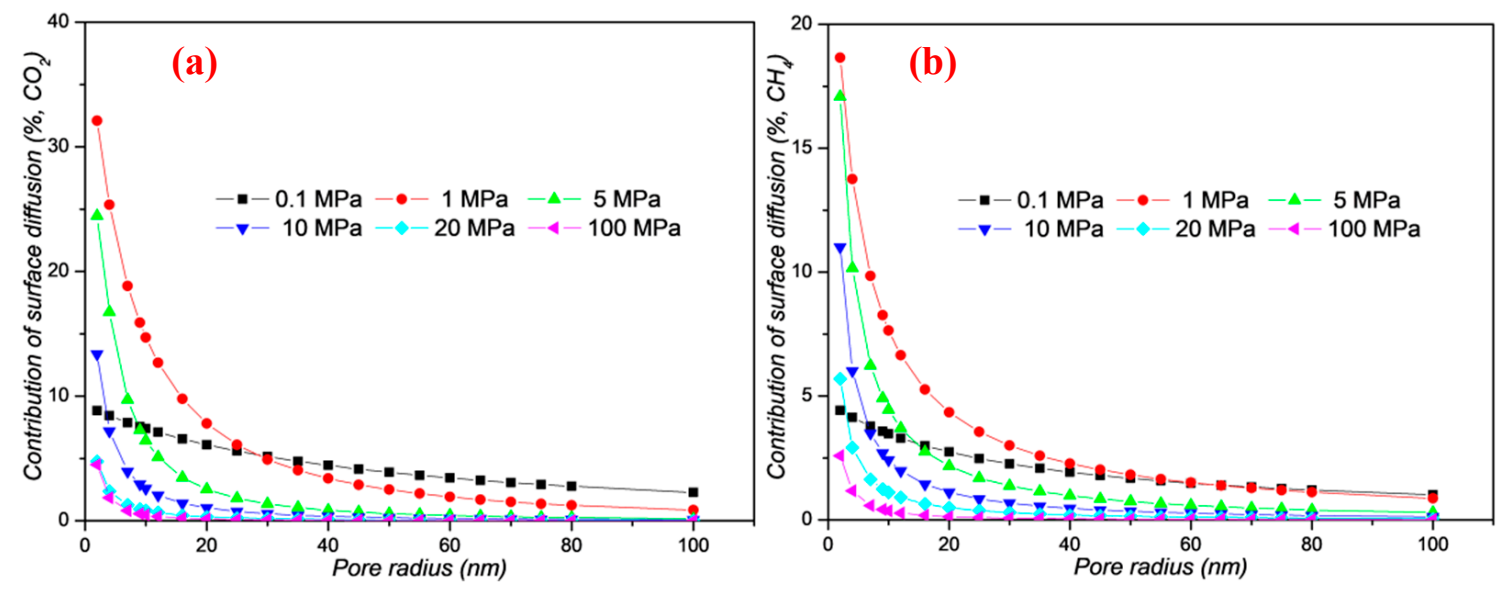

Figure 8. $(\mathbf{a}, \mathbf{b})$ Contribution of surface diffusion to the gas permeability vs. pore radius.
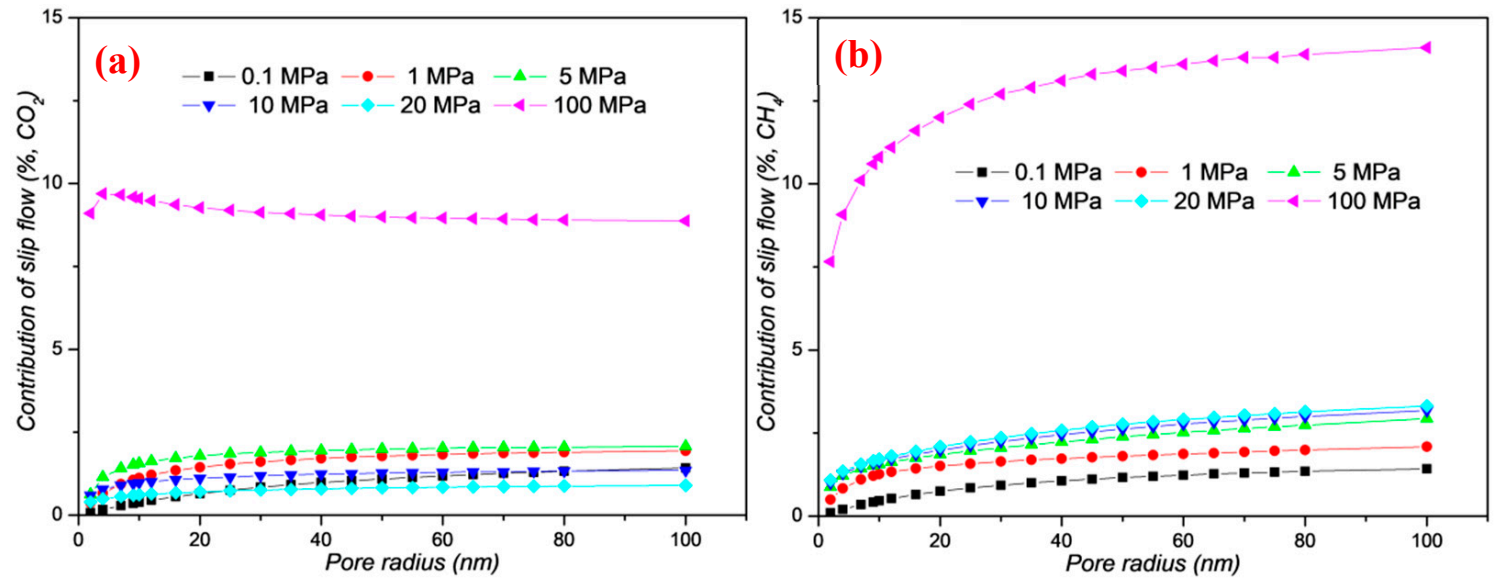

Figure 9. $(\mathbf{a}, \mathbf{b})$ Contribution of slip flow to the gas permeability vs. pore radius.

The contribution of molecular diffusion to the permeability $\left(\gamma_{m(i)}\right)$ for methane and carbon dioxide is shown in Figure 10. As it can be found from Figure 10, the contribution of molecular diffusion decreases with the increase of pore radius, and the effect of pore radius is more obvious under low pressure (Figure 10). On the contrary, the contribution of viscous flow to the permeability $\left(\gamma_{v s(i)}\right)$ increases with the increase of pore radius. As the pressure decreases, the effect of the pore radius becomes more weakened (Figure 11). When the pressure is $0.1 \mathrm{MPa}$, the gas transport caused by molecular diffusion in two-component gas takes the dominate position in pores of radius $2-25 \mathrm{~nm}$, and the weight is up to $88.83 \%$ (Figure 10). Under the same condition, the contribution of viscous flow is almost neglected (Figure 11). Therefore, the collision is mostly between methane and carbon dioxide molecules in atmospheric pressure. The contribution of molecular diffusion to the permeability is lower than $1.41 \%$ under high pressure and in macropores (Figure 10), which means that this transport mechanism can be ignored. 

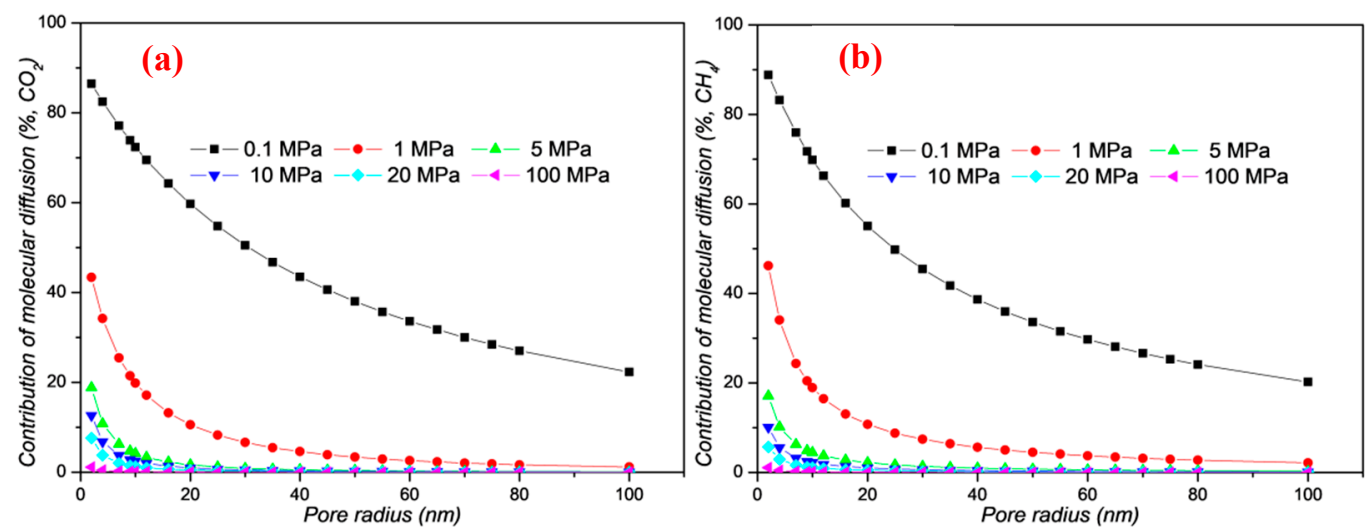

Figure 10. $(\mathbf{a}, \mathbf{b})$ Contribution of molecular diffusion to the gas permeability vs. pore radius.
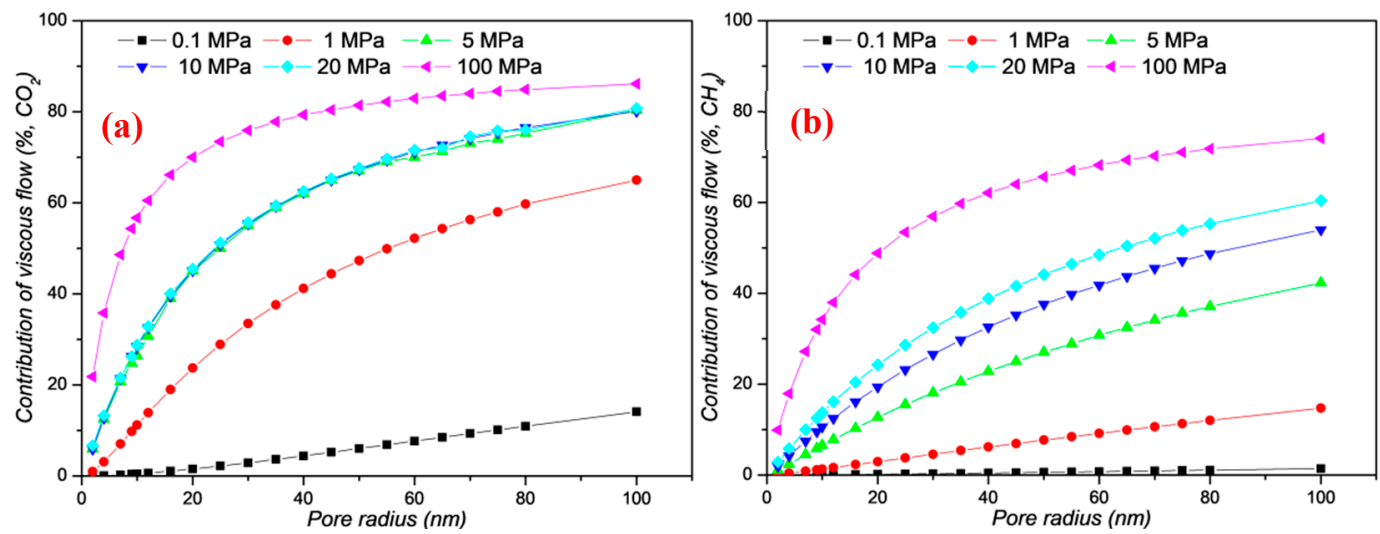

Figure 11. $(\mathbf{a}, \mathbf{b})$ Contribution of viscous flow to the gas permeability vs. pore radius.

\subsection{Effect of Temperature and Fraction of Organic Nanopores}

As it can be found from Equation (38), the temperature $(T)$ and fraction of organic nanopores $(\eta)$ also affect the two-component gas permeability. The collision integrals $\left(\Omega_{A B}\right)$ of two-component gas vary with temperatures. Due to high computational cost, complex analysis, and so on, the collision integrals are usually obtained from the published table rather than by calculation. Figure 12 shows the collision integral of $\mathrm{CH}_{4}-\mathrm{CO}_{2}$ molecules at different temperatures [39]. By using the $\Omega_{A B}$ and $\eta$, the effect of temperature and organic nanopore fraction on the gas permeability can be analyzed.

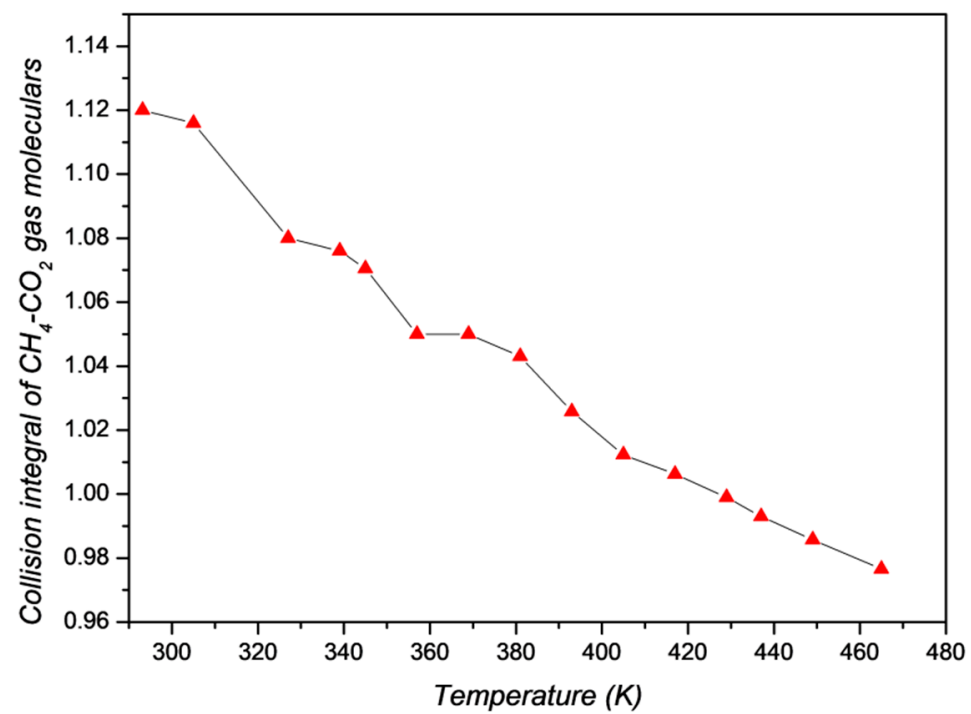

Figure 12. Collision integration of $\mathrm{CH}_{4}-\mathrm{CO}_{2}$ gas molecules at different temperatures. 
As it can be found from Figure 13, the apparent permeability of two-component gas increases with the increase of temperature. The slope of curve is larger when the fraction of organic nanopores increases. Additionally, the effect of temperature on the apparent permeability is greater as the fraction of organic nanopores increases (Figure 13). This means that the effect of temperature on the permeability of two-component gas is more obvious in shales of organic-rich pores. The gas is mainly adsorbed in organic pores [8]. Under the same conditions, there will be more adsorption sites for gas adsorption if the fraction of organic nanopores increases. When the temperature increases, more gas can be desorbed and permeability can be increased. In addition, the effect of temperature and organic nanopore fraction on permeability ratio (PR) of methane and carbon dioxide was analyzed, which is shown in Figure 14. It can be found that the PR of methane increases with temperature and the PR of carbon dioxide decreases with temperature. This indicates that with temperature increasing, the selective adsorption becomes more obvious. More methane is desorbed from the surface of the nanopores and more carbon dioxide is adsorbed on the surface of the nanopores (Figure 14). The gas recovery will be enhanced in shale gas reservoirs.
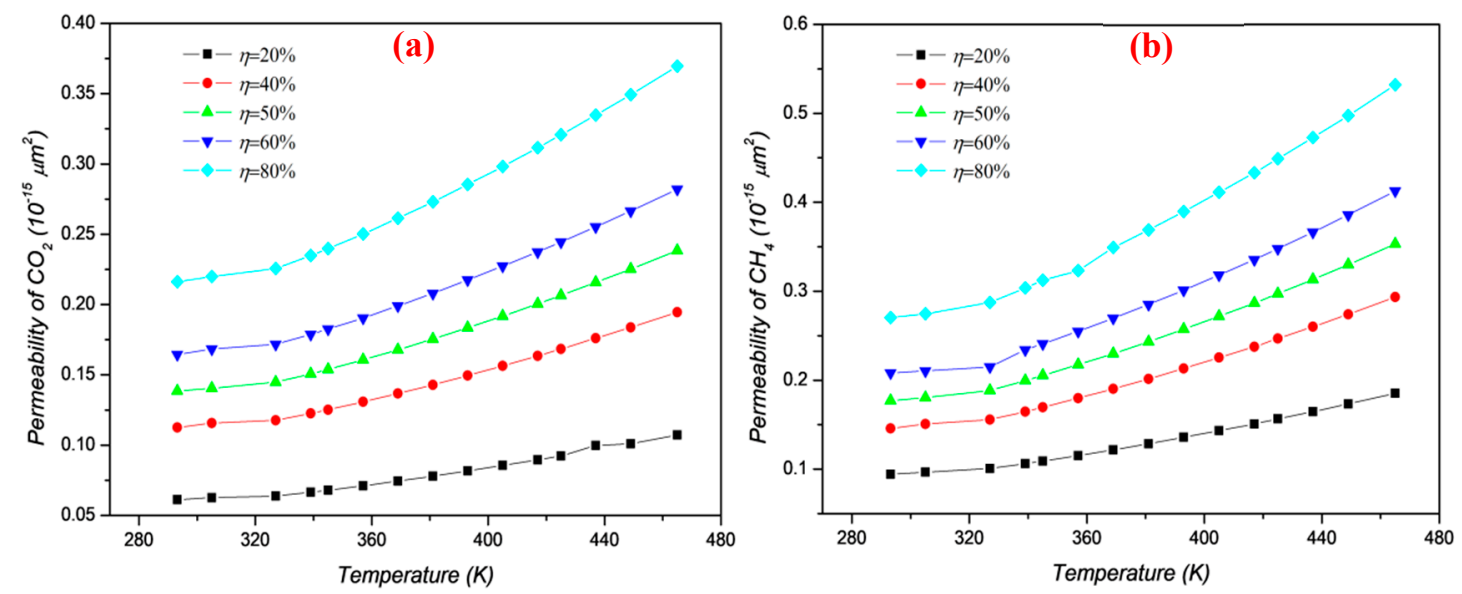

Figure 13. (a,b) Change of gas permeability with different organic nanopore fraction and temperature. Pressure is $1 \mathrm{MPa}$; pore radius is $25 \mathrm{~nm}$; and the component ratio $\left(\mathrm{y}_{\mathrm{CH} 4}: \mathrm{y}_{\mathrm{CO} 2}\right)$ is $7: 3$.

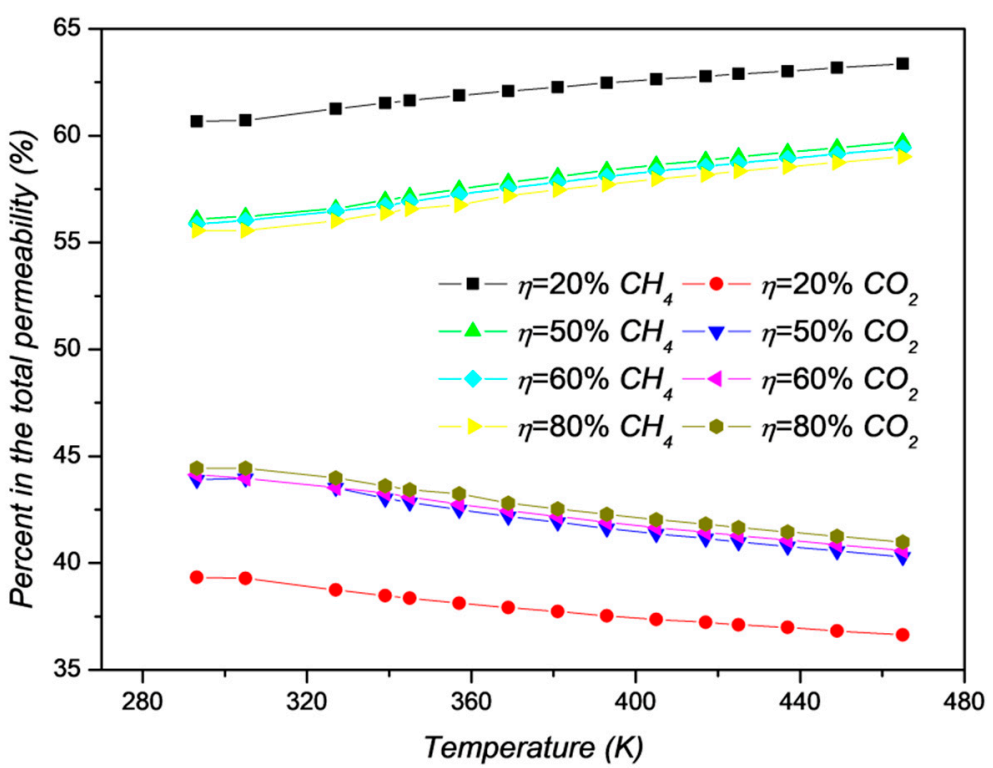

Figure 14. Change of permeability ratio with different organic nanopore faction and temperature. Pressure is $1 \mathrm{MPa}$, pore radius is $25 \mathrm{~nm}$, and the component ratio $\left(\mathrm{y}_{\mathrm{CH} 4}: \mathrm{y}_{\mathrm{CO}}\right)$ is $7: 3$. 


\subsection{Effect of Gas Concentration}

During the dynamic flooding process in $\mathrm{CO}_{2}$-EGR, the concentration ratio of methane to carbon dioxide is changing with time. Therefore, it is necessary to understand the effect of gas concentration ratio on the gas permeability. The permeability curve of two-component gas under different gas concentration ratios is shown in Figure 15. As it can be found from Figure 15a, the apparent permeability of carbon dioxide continuously decreases with the increase of $\mathrm{y}_{\mathrm{CO} 2}$. When $\mathrm{y}_{\mathrm{CO} 2}$ increases from $10 \%$ to $30 \%$ especially, the apparent permeability of carbon dioxide decreases sharply. However, the concentration of carbon dioxide continues to increase, and the decrease of apparent permeability is not obvious. The apparent permeability of methane continues to increase with the decreasing concentration of methane. However, when $\mathrm{y}_{\mathrm{CH} 4}$ decreases from $90 \%$ to $50 \%$, the apparent permeability of methane does not increase significantly. The apparent permeability of methane increases significantly when $\mathrm{y}_{\mathrm{CH} 4}$ decreases continuously from $50 \%$ to $10 \%$. This also reflects the process of injecting carbon dioxide to displace $\mathrm{CH}_{4}$, in which the concentration of carbon dioxide is increasing and the concentration of methane is decreasing. The permeability of carbon dioxide is becoming lower and the permeability of methane is becoming higher.
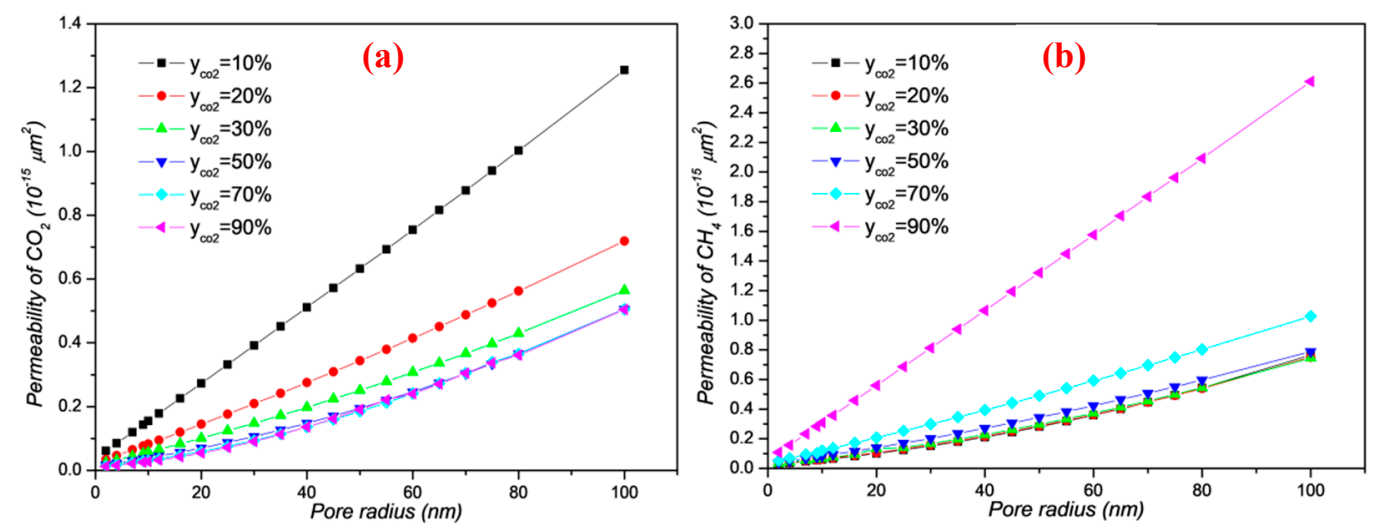

Figure 15. $(\mathbf{a}, \mathbf{b})$ Permeability curve of two-component gas under different gas concentration ratios. The pressure is $1 \mathrm{MPa}$, the temperature is $345 \mathrm{~K}$, and the faction of nanopores is $40 \%$.

The permeability ratio (PR) of methane and carbon dioxide under different concentration ratios is plotted in Figure 16. Initially, the ratio of two-component gas concentration ( $\mathrm{yCH}_{\mathrm{CH}}: \mathrm{yCO}_{\mathrm{CO}}$ ) is 9:1 and 8:2. At this time, the carbon dioxide has just entered the shale matrix, and methane is rarely desorbed from the pore surface. Thus, the apparent permeability ratio of carbon dioxide is higher under these conditions. However, when $\mathrm{y}_{\mathrm{CH} 4}: \mathrm{y}_{\mathrm{CO} 2}=7: 3$, the permeability ratio of $\mathrm{CH}_{4}$ is higher than $50 \%$. This indicates that the apparent permeability of methane is more than that of carbon dioxide. When methane continuously desorbs, the carbon dioxide is adsorbed on the surface of pore wall which leads to the decrease of carbon dioxide permeability. The permeability ratio of methane gradually increases with the decrease of gas concentration. It expresses that more methane adsorbed on the pore surface is produced. Therefore, it can be predicted that more methane can be produced with the gas concentration ratio decreasing continuously. This also shows that carbon dioxide injection is a feasible method to enhance gas recovery in shale gas reservoirs. 

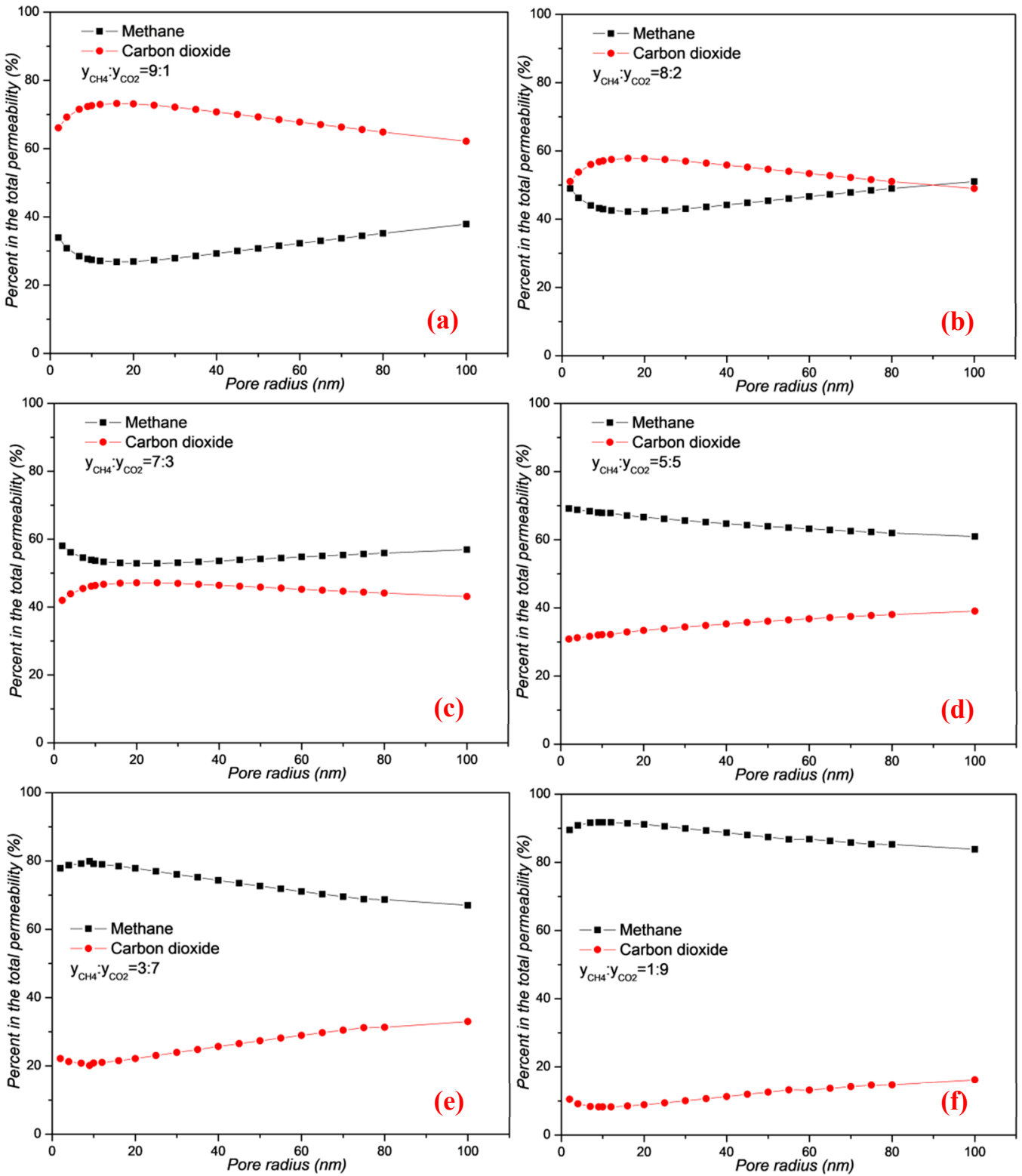

Figure 16. (a-f) Two-component gas permeability ratio under different gas concentration ratios. The pressure is $1 \mathrm{MPa}$, the temperature is $345 \mathrm{~K}$, and the faction of nanopores is $40 \%$.

\section{Conclusions}

In this work, the two-component gas transport model for $\mathrm{CO}_{2}$-EGR was constructed. The inorganic and organic nanopores in the shale matrix were assumed to be circular tube and slits, respectively. Various gas transport mechanisms were considered, such as Knudsen diffusion, molecular diffusion, viscous flow, surface diffusion, and slip flow. The apparent permeability models of the two-component gas were established. The main conclusions of this study are as follows:

(1) The apparent permeability of two-component gas is negatively correlated with pressure, and positively related with pore radius, temperature, organic nanopore fraction. As the gas concentration ratio $\left(\mathrm{y}_{\mathrm{CH} 4}: \mathrm{y}_{\mathrm{CO} 2}\right)$ decreases, the apparent permeability of $\mathrm{CH}_{4}$ increases continuously, while the apparent permeability of $\mathrm{CO}_{2}$ decreases.

(2) The contributions of various mechanisms are revealed for total apparent permeability in shale. (a) As the pore radius increases, the apparent permeability due to Knudsen diffusion increases initially, followed by a decrease under low pressure. The peak of the curve is closer to the y axis with pressure increasing. The apparent permeability due to Knudsen diffusion decreases with pore radius increasing 
under high pressure. (b) Surface diffusion contributes up to 5.68\% to gas transport under high pressure. (c) Molecular diffusion contributes significantly to gas transport, up to $88.83 \%$ under low pressure and in mesopores. The contribution of molecular diffusion to gas transport is less than $1.41 \%$ under high pressure and in macropores, which can be ignored. (d) The contribution of the slip flow is very small under low pressure, which almost closes to zero. (e) For two-component gas, the contribution of viscous flow is more than $46.36 \%$ to the gas transport under high pressure and in macropores, and the highest can reach $86.07 \%$. The contribution of viscous flow is less than $14.6 \%$ for methane under low pressure. However, when pressure is only $0.1 \mathrm{MPa}$, the contribution of viscous flow is less than $14.12 \%$ to gas transport for carbon dioxide.

(3) The influencing factors of the permeability ratio (PR) were analyzed for two-component gas. The PR of methane decreases with pressure increasing. As the fraction of organic nanopores increases, the PR of methane does not change significantly. The PR of methane decreases slightly when the fraction of organic nanopores increases from $20 \%$ to $50 \%$. The PR of methane increases with the decrease of methane concentration. For the carbon dioxide, the change of PR with various influencing factors is opposite compared with methane.

Author Contributions: Conceptualization, C.G. and R.L.; methodology, C.G.; validation, R.L., X.W., and H.L.; formal analysis, R.L.; investigation, C.G. and R.L.; writing, R.L.; review and editing, C.G.; project administration, C.G. All authors have read and agreed to the published version of the manuscript.

Funding: This research was funded by National Natural Science Foundation of China: No. 51704265, No. 51504146, the Outstanding Talent Development Project of China University of Geosciences (CUG20170614); and the Fundamental Research Foundation for National University, China University of Geosciences (Wuhan) (1810491A07).

Acknowledgments: The authors acknowledge supports from National Natural Science Foundation of China: No. 51704265 (Research on two component gas diffusion-convection model in enhancing shale gas recovery with $\mathrm{CO}_{2}$ injection PI: Chaohua Guo); No. 51504146 (PI: Xin Wang); the Outstanding Talent Development Project of China University of Geosciences (CUG20170614); and the Fundamental Research Founds for National University, China University of Geosciences (Wuhan) (1810491A07).

Conflicts of Interest: The authors declare no conflict of interest.

\section{References}

1. Guo, C.; Liu, H.; Xu, L.; Zhou, Q. An improved transport model of shale gas considering three-phase adsorption mechanism in nanopores. J. Pet. Sci. Eng. 2019, 182, 106291. [CrossRef]

2. Boyer, C.; Kieschnick, J.; Suarez-Rivera, R. Producing gas from its source. Oilfield Rev. 2006, 18, 36-49.

3. Jung, C.; Zhou, J.; Chenevert, M.; Sharma, M.M. The impact of shale preservation on the petrophysical properties of organic-rich shales. In Proceedings of the SPE Annual Technical Conference and Exhibition, SEP 20-OCT 2, New Orleans, LA, USA, 30 September-2 October 2013.

4. Hu, Y.; Devegowda, D.; Striolo, A.; Phan, A.; Ho, T.A.; Civan, F.; Sigal, R.F. Microscopic dynamics of water and hydrocarbon in shale-kerogen pores of potentially mixed-wettability. Paper Presented at SPE Unconventional Resources Conference, Calgary, AB, Canada, 5-7 November 2013.

5. Li, J.; Li, X.; Wu, K. Thickness and stability of water film confined inside nanoslits and nanocapillaries of shale and clay. Int. J. Coal Geol. 2017, 179, 253-268. [CrossRef]

6. Korb, J.; Nicot, B.; Louis-Joseph, A. Dynamics and wettability of oil and water in oil shales. J. Phys. Chem. C 2014, 118, 23212-23218. [CrossRef]

7. Jin, Z.; Firoozabadi, A. Effect of water on methane and carbon dioxide sorption in clay minerals by Monte Carlo simulations. Fluid Phase Equilibria 2014, 382, 10-20. [CrossRef]

8. Wang, Y.; Zhu, Y.; Liu, S. Pore characterization and its impact on methane adsorption capacity for organic-rich marine shales. Fuel 2016, 181, 227-237. [CrossRef]

9. Wang, J.; Luo, H.; Cao, F. An integrative model to simulate gas transport and production coupled with gas adsorption, non-Darcy flow, surface diffusion, and stress dependence in organic-shale reservoirs. SPE J. 2017, 22, 244-264. [CrossRef]

10. Feng, Q.; Xu, S.; Wang, S. Apparent permeability model for shale oil with multiple mechanisms. J. Pet. Sci. Eng. 2019, 175, 814-827. [CrossRef] 
11. Song, W.; Yao, J.; Ma, J.; Couples, G.; Li, Y. Assessing relative contributions of transport mechanisms and real gas properties to gas flow in nanoscale organic pores in shales by pore network modelling. Int. J. Heat Mass Transf. 2017, 113, 524-537. [CrossRef]

12. Cai, J.; Lin, D.; Singh, H.; Zhou, S.; Meng, Q.; Zhang, Q. A simple permeability model for shale gas and key insights on relative importance of various transport mechanisms. Fuel 2019, 252, 210-219. [CrossRef]

13. Singh, H.; Javadpour, F.; Ettehadtavakkol, A. Nonempirical Apparent Permeability of Shale. SPE Reserv. Eval. Eng. 2014, 17, 414-424. [CrossRef]

14. Wu, K.; Chen, Z.; Li, X.; Guo, C.; Wei, M. A model for multiple transport mechanisms through nanopores of shale gas reservoirs with real gas effect-adsorption-mechanic coupling. Int. J. Heat Mass Transf. 2016, 93, 408-426. [CrossRef]

15. Javadpour, F. Nanopores and apparent permeability of gas flow in mudrocks (shales and siltstone). J. Can. Pet. Technol. 2009, 48, 16-21. [CrossRef]

16. Darabi, H.; Ettenhad, A.; Javadpour, F. Gas flow in ultra-tight shale strata. J. Fluid Mech. 2012, 710, 641-658. [CrossRef]

17. Zhang, Y.; Li, D.; Sun, X.; Shi, D.; Su, Y. A new model for calculating the apparent permeability of shale gas in the real state. Nat. Gas Ind. B 2018, 5, 245-252. [CrossRef]

18. Xu, S.; Feng, Q.; Wang, S.; Li, Y. A 3D multi-mechanistic model for predicting shale gas permeability. J. Nat. Gas Sci. Eng. 2019, 68, 102913. [CrossRef]

19. Li, Z.; Elsworth, D. Controls of $\mathrm{CO}_{2}-\mathrm{N}_{2}$ gas flood ratios on enhanced shale gas recovery and ultimate $\mathrm{CO}_{2}$ sequestration. J. Pet. Sci. Eng. 2019, 179, 1037-1045. [CrossRef]

20. Fathi, E.; Akkutlu, I. Multi-component gas transport and adsorption effects during $\mathrm{CO}_{2}$ injection and enhanced shale gas recovery. Int. J. Coal Geol. 2014, 123, 52-61. [CrossRef]

21. Kang, S.; Fathi, E.; Ambrose, R.; Akkutlu, I.Y.; Sigal, R.F. Carbon dioxide storage capacity of organic-rich shales. SPE J. 2011, 16, 842-855. [CrossRef]

22. Sun, H.; Yao, J.; Gao, S.H.; Fan, D.Y.; Wang, C.C.; Sun, Z.X. Numerical study of $\mathrm{CO}_{2}$ enhanced natural gas recovery and sequestration in shale gas reservoirs. Int. J. Greenh. Gas Control 2013, 19, 406-419. [CrossRef]

23. Afsharpoor, A.; Javadpour, F. Liquid slip flow in a network of shale noncircular nanopores. Fuel 2016, 180, 580-590. [CrossRef]

24. Ji, L.; Lin, M.; Jiang, W.; Cao, G.; Zhou, J.; Luo, C. Investigation into the apparent permeability and gas-bearing property in typical organic pores in shale rocks. Mar. Pet. Geol. 2019, 110, 871-885. [CrossRef]

25. Chen, M.; Kang, Y.; Li, X.; Wang, W.; Yang, B.; Liu, H. Investigation of multi-scale gas transport behavior in organic-rich shale. J. Nat. Gas Sci. Eng. 2016, 36, 1188-1198. [CrossRef]

26. Li, J.; Li, X.; Wang, X.; Li, Y.; Wu, K.; Shi, J.; Yu, P. Water distribution characteristic and effect on methane adsorption capacity in shale clay. Int. J. Coal Geol. 2016, 159, 135-154. [CrossRef]

27. Aylmore, L.; Quirk, J. The micropore size distributions of clay mineral systems. Eur. J. Soil Sci. 1967, 18, 1-17. [CrossRef]

28. Javadpour, F.; Fisher, D.; Unsworth, M. Nanoscale gas flow in shale gas Sediments. J. Can. Pet. Technol. 2007, 46, 55-61. [CrossRef]

29. Florence, F.; Rushing, J.; Newsham, K.; Blasingame, T.A. Improved permeability prediction relations for low permeability sands. Paper Presented at SPE Rocky Mt. Oil Gas Technol. Symp., Denver, CO, USA, 16-18 April 2007.

30. Wu, K.; Li, X.; Wang, C.; Yu, W.; Chen, Z. Model for surface diffusion of adsorbed gas in nanopores of shale gas reservoirs. Ind. Eng. Chem. Res. 2015, 54, 3225-3236. [CrossRef]

31. Chen, Y.; Yang, R. Concentration dependence of surface diffusion and zeolitic diffusion. Aiche J. 1991, 37, 1579-1582. [CrossRef]

32. Wu, K.; Li, X.; Wang, C.; Chen, Z.; Yu, W. A model for gas transport in microfractures of shale and tight gas reservoirs. Aiche J. 2015, 61, 2079-2088. [CrossRef]

33. Milliken, K.; Rudnicki, M.; Awwiller, D.; Zhang, T. Organic matter-hosted pore system, Marcellus Formation (Devonian), Pennsylvania. AAPG Bull. 2013, 97, 177-200. [CrossRef]

34. Civan, F.; Rai, C.; Sondergeld, C. Shale-gas permeability and diffusivity inferred by improved formulation of relevant retention and transport mechanisms. Transp. Porous Media 2011, 86, 925-944. [CrossRef]

35. Song, W.; Yao, J.; Li, Y.; Sun, H.; Zhang, L.; Yang, Y.; Sui, H. Apparent gas permeability in an organic-rich shale reservoir. Fuel 2016, 181, 973-984. [CrossRef] 
36. Wu, K.; Chen, Z.; Li, X.; Xu, J.; Li, J.; Wang, K.; Dong, X. Flow behavior of gas confined in nanoporous shale at high pressure: Real gas effect. Fuel 2017, 205, 173-183. [CrossRef]

37. Feng, C. Effects of $\mathrm{CO}_{2}$ and $\mathrm{CH}_{4}$ mixture binary gas on permeability of shale. J. Hunan Univ. Sci. Technol. 2017, 32, 1-5.

38. Erfan, M.; Hassan, H.; Chen, Z. Estimation of shale apparent permeability for multimechanistic, multicomponent gas production using rate transient analysis. Energy Fuels 2019, 33, 1990-1997.

39. Cussler, E. Diffusion: Mass Fransfer in Fluid Systems, 3rd ed.; Cambridge University Press: Cambridge, UK, 1997; pp. 117-160.

(C) 2020 by the authors. Licensee MDPI, Basel, Switzerland. This article is an open access article distributed under the terms and conditions of the Creative Commons Attribution (CC BY) license (http://creativecommons.org/licenses/by/4.0/). 